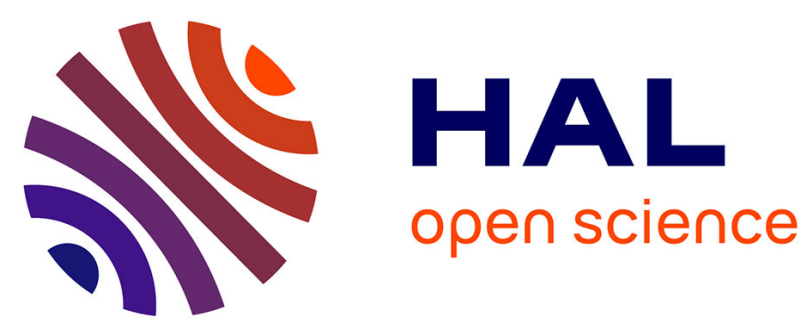

\title{
Quantitative measurement of volume fraction profiles of soot of different maturities in premixed flames by extinction-calibrated laser-induced incandescence
}

Christopher Betrancourt, Xavier Mercier, Fengshan Liu, Pascale Desgroux

\section{To cite this version:}

Christopher Betrancourt, Xavier Mercier, Fengshan Liu, Pascale Desgroux. Quantitative measurement of volume fraction profiles of soot of different maturities in premixed flames by extinction-calibrated laser-induced incandescence. Applied Physics B - Laser and Optics, 2019, 125 (1), 10.1007/s00340018-7127-2 . hal-02315805

\section{HAL Id: hal-02315805 \\ https://hal.univ-lille.fr/hal-02315805}

Submitted on 12 Nov 2020

HAL is a multi-disciplinary open access archive for the deposit and dissemination of scientific research documents, whether they are published or not. The documents may come from teaching and research institutions in France or abroad, or from public or private research centers.
L'archive ouverte pluridisciplinaire HAL, est destinée au dépôt et à la diffusion de documents scientifiques de niveau recherche, publiés ou non, émanant des établissements d'enseignement et de recherche français ou étrangers, des laboratoires publics ou privés. 


\title{
Quantitative measurement of volume fraction profiles of soot of different maturities in premixed flames by extinction-calibrated laser-induced incandescence
}

\author{
Christopher Betrancourt ${ }^{1 !}$, Xavier Mercier $^{1}$, Fengshan Liu ${ }^{2}$, Pascale Desgroux ${ }^{1 *}$
}

Affiliation

${ }^{1}$ Univ. Lille, CNRS, UMR 8522 - PC2A - Physicochimie des Processus de Combustion et de l'Atmosphère, F-59000 Lille, France

${ }^{2}$ Measurement Science and Standards, National Research Council, Ottawa, Ontario, Canada

Email addresses of the authors

! C. BETRANCOURT: on leave from Univ. Lille. Present address CORIA, betrancourt.c@gmail.com

X.MERCIER: $\quad$ xavier.mercier@univ-lille1.fr

F. LIU : $\quad$ Fengshan.Liu@nrc-cnrc.gc.ca

*Corresponding author: Pascale Desgroux

pascale.desgroux@univ-lille1.fr; Tel : +33(0)320434930 ; FAX :+33(0)320436977

Laboratoire PC2A, Bâtiment C11, Université des Science et Technologies de Lille, 59655 Villeneuve d'Ascq, France

\begin{abstract}
The Laser Induced Incandescence (LII) and Cavity Ring-Down Extinction (CRDE) optical techniques offer excellent sensitivity to allow in situ soot volume fraction $\left(f_{\mathrm{v}}\right)$ measurements over a wide dynamic range. The objective of this work is to quantitatively measure the axial $f_{\mathrm{v}}$ profiles in two nbutane premixed flames with very different stages of soot maturity and very different levels of $f_{\mathrm{v}}$. The first flame is a nucleation flame in which soot particles undergo only minor growth and have diameters between 2 to $4 \mathrm{~nm}$. The second is a normal sooting flame generating soot from inception to mature stage. Experiments were performed by combining LII and CRDE using a laser at $1064 \mathrm{~nm}$. Quantitative measurements of $f_{\mathrm{v}}$ require the knowledge of the dependence of soot absorption function $E(m)$ on wavelength and soot maturity. To this aim, two novel approaches were developed to evaluate the variation of $E(m)$ at $1064 \mathrm{~nm}$ along the flame centerline and between 532 to 1064 $\mathrm{nm}$ covering the entire spectral range used in this study. The axial LII profiles were converted to absolute $f_{v}$ by CRDE measurements. The performance of the combined techniques is demonstrated in the two investigated flames for $f_{\mathrm{v}}$ in the range of $0.013-9.7 \mathrm{ppb}$.
\end{abstract}




\section{Introduction}

There is a critical need to develop generic kinetics models able to predict soot formation and oxidation in different combustion systems and for different fuels. Unfortunately, the detailed physical and chemical processes involved in soot nucleation from gaseous precursor species to incipient soot and subsequent surface growth remain elusive $[1,2]$. The lack of accurate and in situ measurement techniques to follow the early evolution of incipient soot size below $10 \mathrm{~nm}$ impedes our understanding of soot nucleation and early growth and therefore the validation of soot formation models. Extended experimental databases with gaseous species concentrations, soot volume fractions $\left(f_{\mathrm{v}}\right)$, and soot size distributions in steady laminar flames are exceedingly required for the purpose of soot model evaluation. Particularly the ability of a flame model to describe the evolution of $f_{\mathrm{v}}$ over a wide dynamic range constitutes a good indicator of its performances [3]. This aspect is especially challenging in the case of soot particles as it imposes a severe test to the sensitivity and accuracy of the experimental technique for the determination of $f_{\mathrm{v}}$ over several orders of magnitude. Although the scanning mobility particle sizer (SMPS) has been increasingly used to measure the size distribution of soot particles in laminar [4-7] and turbulent flames [8], optical techniques, such as extinction $[9,10]$ or laser induced incandescence (LII) [11-13], are still preferred, since these methods are either non-intrusive in the case of light extinction or weakly-intrusive in the case of LII at high fluence.

The principle of extinction is fairly straightforward and well established. It consists in detecting the line-of-sight attenuation of light intensity (at wavelength $\lambda$ ) across the flame to obtain the local extinction coefficient $K_{\text {ext }}$ based on the Beer-Lambert law. If the contribution of scattering to extinction is negligible in comparison to absorption, the local soot volume fraction $f_{\mathrm{v}}$ is directly related to the local extinction coefficient through $f_{\mathrm{v}}=\lambda \mathrm{K}_{\text {ext }} /(6 \pi E(m))$, where $\mathrm{m}$ is the refractive index of the soot particles at the wavelength of the light source and $E(m)$ the soot absorption function [14]. It should be noted that the extinction coefficient $K_{\text {ext }}$ should not be confused with the dimensionless extinction coefficient in the literature, e.g. [15]. The principle of LII consists in heating 
soot particles using a high power pulsed laser, though a continuous-wave laser can also be used in LII $[16,17]$, by taking the advantage of the highly absorbing property of soot particles. The absorption of laser energy leads to a rapid increase in the internal energy of soot particles and hence their temperatures typically rise to $3500-4200 \mathrm{~K}[13,18,19]$, depending on the thermal and optical properties of soot particles (efficiency of absorption, specific heat $c_{s}$, and density $\rho_{s}$ ) and the laser fluence. After the laser pulse, soot particles cool down by sublimation and conduction to the surrounding gas temperature [20]. Although the thermal emission associated with the elevated temperature of soot particles contributes negligibly to their cooling, it provides the incandescence signal as the basis of LII. This incandescence emission follows the Planck law and is modified by the emission property of soot particles at the detection wavelength. Through the application of the Rayleigh-Debye-Gans theory to soot fractal aggregates [21], the LII signal, i.e., the thermal incandescence intensity, can be related to the soot volume fraction $f_{\mathrm{v}}$ in the detection volume. Therefore, the relationship between $K_{\text {ext }}$ or the LII signal and $f_{\mathrm{V}}$ is directly linked to the value of $E(m)$. The accurate determination of $E(m)$ in the visible and near infrared spectrum remains challenging and its value is subject to a large scatter in the literature, depending on the technique used for its determination and the fuel and flame conditions. However, two tendencies have emerged based on recent experimental studies: a decrease of $E(m)$ with decreasing wavelength in the UV and visible range below about $500 \mathrm{~nm}$ followed by a nearly constant value between about 500 and $1100 \mathrm{~nm}$ $[14,22,23]$ and an increase of $E(m)$ in premixed flames with increasing soot maturity, which is associated with the residence time of soot in flame [11-13]. These tendencies are also observed in diffusion flames $[24,25]$. Nevertheless, the determination of $E(m)$ remains the stumbling block for accurate soot measurements using optically-based techniques. In almost all the experimental data of $f_{\mathrm{v}}$ reported in the literature, $E(\mathrm{~m})$ is implicitly considered as a constant spatially in flames. Besides the variability of $E(m)$, the accurate knowledge of the variation of specific heat $c_{s}$ and bulk density $\rho_{s}$ of soot with the stage of maturity also remains a challenge. 
In this work we aim to measure quantitatively the soot volume fraction over a large dynamic range ( 1000) with primary soot particle diameters from 2 to around $16 \mathrm{~nm}$, i.e., of increasing maturity. To achieve this objective we used a highly sensitive LII technique calibrated by extinction. The main question to be addressed in this paper is "how to quantitatively relate the variation of LII signal, over a large dynamic range and a large range of soot maturity from newly formed soot to fairly mature soot, to the variation of soot volume fraction as accurately as possible?" In our previous studies [2629] we emphasized the existence of soot particles as small as 2 to $4 \mathrm{~nm}$ that are able to absorb 1064 $\mathrm{nm}$ radiation and to radiate spectrally continuous blackbody-type radiation [26]. These particles were named "incipient soot" or "nascent soot" according to their ability to absorb visible and near-infrared radiation [26-29]. Such a definition of "incipient soot" was inspired by the definition introduced by D'Alessio et al. [30] who stated: "The definitions of soot and the combustion conditions considered to mark the onset of soot are operational, and they depend on the measurement technique used and its detection limits, similar to the problem of exactly defining $O C$ and EC in atmospheric PM measurements". The same group later defined the soot formation threshold as "the $C / O$ value where light absorption in the visible and Laser Induced Incandescence are detected" [31]. In this work, the soot particles identified from their incandescence induced by $1064 \mathrm{~nm}$ radiation absorption will be named "smallest incandescent soot particles" to avoid potential confusion with the less well-defined term "incipient soot". It is noted that the relationship between the smallest incandescent soot particles and incipient soot deserves further investigations once a clear definition of incipient soot is established. The largest soot particles measured in this study have experienced significant growth and are defined as mature soot [26].

To achieve the objective of this study we investigated two n-butane atmospheric premixed flames in which the soot particle size distributions have been recently measured by combining time-resolved LII, SMPS, and analysis of helium ion microscopy (HIM) images of sampled soot particles [26]. The 
first flame is a nucleation flame (equivalence ratio $\phi=1.75$ ) that produces very low concentrations of soot particles of very small size which undergo only minor soot surface growth along the flame. The second (normal) flame is more sooting $(\phi=1.95)$ and the soot particles undergo typical surface growth, coagulation, and aggregation. The existence of nucleation flames that produce only soot particles in the diameter range of 2-4 $\mathrm{nm}$ without significant surface growth and aggregation has been demonstrated recently [26-29]. According to [26] the diameter of the smallest incandescent soot particles in the present investigated flames is within 2-4 $\mathrm{nm}$. These smallest incandescent soot particles are present over a wide range of heights above the burner exit in the nucleation flames or start to appear in the nucleation zone of normal sooting flames.

Nucleation flames constitute a promising flame configuration to gain insights into the soot nucleation step and to validate soot nucleation model $[3,27,32]$. In our recent work [26] the thermal and optical parameters of the smallest incandescent soot particles were determined from matching the predicted time-resolved normalized LII signals and soot temperature to the measured ones. From this work, it appeared that those parameters of the smallest incandescent soot particles are not drastically different from those of mature soot. Specifically, $E(m)$ and density of the smallest incandescent soot are lower than those of mature soot by about $42 \%$ and $28 \%$, respectively. The value of $E(m)$ at $1064 \mathrm{~nm}$ in the nucleation flame was found from 0.23 to 0.26 in the zone of 7 to 10 $\mathrm{mm}$ above the burner, which agrees well with the values determined for soot particles in the nucleation zone of various atmospheric premixed flames $[11,12]$. It should be pointed out that such $E(m)$ values were obtained under the specific assumptions about the values of soot density and specific heat $[11,12,26]$.

It is important to point out that it is critical to know the value of $E(m)$ to measure quantitatively the $f_{\mathrm{v}}$ profiles from the smallest incandescent soot to mature soot in the two sooting flames mentioned above. The strategy followed in this study allows to minimize the impact of $E(m)$ uncertainty in absorption and in emission (at the collection wavelength used in LII) to improve the accuracy in the determination of $f_{\mathrm{v}}$. To this aim, the LII signal profiles obtained using $1064 \mathrm{~nm}$ laser 
excitation in the two flames, i.e., different soot maturities, were converted to relative $f_{\mathrm{v}}$ by considering the following three important factors: (1) the variation of the heated soot temperature along the flames, (2) the relative variation of $E(m) / \rho_{s} c_{S}$ at $1064 \mathrm{~nm}$ with height above burner exit $(\mathrm{HAB})$, and (3) the spectral variation of $E(m)$ in the wavelength range used for detecting the LII emission.

The determination of the variation of $E(m) / \rho_{s} c_{s}$ with $\mathrm{HAB}$ based on the soot temperature rise (above the local gas temperature) curve as a function of laser fluence in the low-fluence regime is one of the original contributions of this work. It is inspired by previous methods reported in the literature that rely on the behavior of LII signal with the laser fluence (fluence curve) to extract in situ information on some physical-chemical parameters of soot. Among these methods, the twoexcitation wavelength LII technique, first introduced by Therssen et al. [33] has been applied to determine the relative spectral variation of the absorption function of soot particles of different maturities in various flames $[25,33-36]$. The method relies on producing identical time-resolved and spectrally resolved LII signals, i.e., identical soot temperature, by adjusting the laser fluence of one of the two lasers of different wavelengths. By drawing the fluence curves obtained at the two wavelengths for given soot particles, the scaling of the fluence is simply obtained by matching the two curves. Bambha et al. [37] introduced a new approach aiming to determine the relative variation of $E(m)$ of soot particles covered by different coatings. By assuming that the absorption function of the core soot and its sublimation temperature are constant regardless of the coating thickness, they demonstrated that the normalized peak LII signal (at one wavelength) variation with fluence is representative of the variation of the particle temperature. Then by analyzing the variation of the fluence curves for different coatings, they could determine the influence of the coating on the LII response. More recently, Johansson et al. [24] extended this methodology to determine the variation of $E(m)$ and $E(m) / \rho_{s} c_{s}$ as a function of soot maturity on the centerline of a coflow diffusion flame. In their work, they considered the deviation of the absorption cross section from the $\lambda^{-1}$ dependence by introducing a dispersion exponent into the expression of $E(m)$, determined from 
the scaling of the peak LII normalized fluence curves at two wavelengths (532 and $1064 \mathrm{~nm}$ ). Similar to the study of Bambha et al. [37], Johansson et al. [24] also analysed the scaling factor to match the normalized peak LII fluence curves obtained at one wavelength at different HABs to deduce the behavior of $E(m)$ and $E(m) / \rho_{s} c_{s}$ as a function of $\mathrm{HAB}$ and soot maturity. This method will be further discussed in Section 4.1.

In this work, the determination of the variation of $E(m) / \rho_{s} c_{s}$ at $1064 \mathrm{~nm}$ with $\mathrm{HAB}$ is deduced from the temperature increase of soot particle above the local gas temperature in the low laser fluence regime leading to the estimation of the relative variation of $E(m)$ with $\mathrm{HAB}$ assuming the product $\rho_{S} c_{S}$ is known. The spectral variation of $E(m)$ is analysed based on the comparison of combined measurements of LII and extinction, which constitutes the second original contribution of this study. Finally, the relative $f_{\mathrm{v}}$ profiles were converted to absolute ones through a calibration procedure done at a particular $H A B$ using the highly sensitive cavity ring-down extinction technique (CRDE), previously named cavity ring-down spectroscopy [38,39].

\section{Experimental set-up}

The burner set-up is detailed in [26]. Two atmospheric premixed $n$-butane $/ \mathrm{O}_{2} / \mathrm{N}_{2}$ flames, stabilized on a $6 \mathrm{~cm}$-diameter bronze porous Holthuis burner, have been investigated. One is a normal sooting flame at $\phi=1.95$ (Flame1.95; 55.39\% $\mathrm{N}_{2}$ ) and the other is the so-called nucleation flame at $\phi=1.75$ (Flame1.75; 55.32\% $\mathrm{N}_{2}$ ). The mixture total flow rate was maintained at 6.71 standard litre/minute (273 K and $1 \mathrm{~atm})$.

The flame temperature profiles along the centerline were measured using the technique of laser induced fluorescence (LIF) on NO species. They are available in the supplement information of [26].

The laser used for the LII and CRDE experiments is a Nd:YAG laser (Quantel Brilliant) operating at $\lambda=1064 \mathrm{~nm}$ with a Gaussian beam of $6 \mathrm{~mm}$ diameter and a repetition rate of $10 \mathrm{~Hz}$. The relative axial $f_{\mathrm{v}}$ profiles were obtained by LII with a laser fluence $\mathrm{F}=0.35 \mathrm{~J} / \mathrm{cm}^{2}$. The relative $f_{\mathrm{v}}$ profiles were 
converted to absolute $f_{\mathrm{v}}$ profiles by a calibration procedure detailed below based on an extinction measurement by CRDE performed at the same wavelength and at $\mathrm{HAB}=10 \mathrm{~mm}$ in both flames.

\subsection{LII measurements}

The LII technique was used to measure the qualitative $f_{\mathrm{v}}$ profiles along both the central axis of the flame (axial profiles) and the radial LII profiles, characterising the $f_{\mathrm{v}}$ distribution along the flame diameter, for different heights above the burner (HAB).

\subsubsection{Axial LII profiles}

Axial LII profiles were obtained using the LII set-up described in [26] and a laser fluence of $0.35 \mathrm{~J} / \mathrm{cm}^{2}$. This set-up was optimized in order to maximize the signal-to-noise ratio for the detection of smallest incandescent soot particles. The optimization relies first on the use of a large measurement volume (located on the flame centerline) selected in the Gaussian laser beam transformed into a nearly tophat fluence distribution profile. The collection volume was selected by imaging the slit placed in front of the PMTs into the top-hat laser beam with two achromatic lenses resulting in a volume of $19 \mathrm{~mm}^{3}$ [26]. The LII emission issued from the collection volume was split with a dichroic mirror (Semrock FF596-DI01) and detected simultaneously by two photomultipliers tubes (PMT) (Hamamatsu R2257), having a risetime of $2.6 \mathrm{~ns}$, which were equipped with interference filters centered respectively at 532 and $650 \mathrm{~nm}$. The two-color time-resolved LII (2C-LII) signals were simultaneously measured at different HABs along the centerline of the two flames. This allows the determination of the temperature of laser-heated soot particles using the principle of two-color pyrometry. It must be noticed that the previous soot temperatures reported in [26] were obtained from spectrally resolved LII measurements with a gated exposure time of $10 \mathrm{~ns}$. In this study, the soot volume fraction and soot temperature measurements were inferred from the prompt LII signals detected with the PMTs with details provided below. As explained in Section 4.1, the soot temperature was needed to interpret the evolution of the prompt LII signals as a function of the laser fluence. The laser fluence was varied between 0 and $0.4 \mathrm{~J} / \mathrm{cm}^{2}$ using an optical attenuator and the soot temperature was 
derived according to the two-color LII method and an assumption of the relative variation of $E(m)$ at the two detection spectral bands to be presented later. The second measure to maximize the LII signal to noise ratio is to place a shutter in front of the collection system ( $20 \mathrm{~ms}$ opening time) to reduce the contribution of the continuous flame emission and prevent saturation of the PMTs. The time-resolved LII signals were recorded by an oscilloscope (LECROY 6050A, 8-bit, $500 \mathrm{MHz}$ bandwidth, $5 \mathrm{GS} / \mathrm{s}$ sampling rate), which was triggered by a photodiode (Hamamatsu S1722-02) measuring the transmitted laser radiation and placed after the burner.

\subsubsection{Radial LII profiles}

The radial LII $\left(f_{\mathrm{v}}\right)$ profile measurements have been carried out in order to determine the extinction pathlength required by the CRDE technique to obtain the mean $f_{\mathrm{v}}$ and to establish the relationship between the radial mean $f_{\mathrm{v}}$ and the axial $f_{\mathrm{v}}$. The latter is required to convert the relative axial $f_{\mathrm{v}}$ profile measured by LII into the absolute $f_{\mathrm{v}}$ profile. A schematic of the $1 \mathrm{D}$ LII imaging set-up used for the radial LII profiles determination is provided in Fig. 1. In order to achieve an adequate vertical resolution and a weak beam divergence, the laser is reduced in size by a factor 5 using two converging lenses $\left(f_{1}=50 \mathrm{~cm}\right.$ and $\left.f_{2}=10 \mathrm{~cm}\right)$ in a telescope configuration. The resulting Gaussian beam (around $1.1 \mathrm{~mm}$ at 1/e) is parallel to the burner surface. Its diameter has been monitored with a beam profiler (Gentec Beamage) and was found constant along the flame diameter. The LII traces were imaged using a CERCO lens (100 mm, F/2.8) coupled to an ICCD camera (Princeton PIMAX Gen III). The camera was triggered by the Q-switch output of the laser. The exposure time was fixed at 10 ns starting at the peak of the laser in all the 1D-LII imaging experiments. 


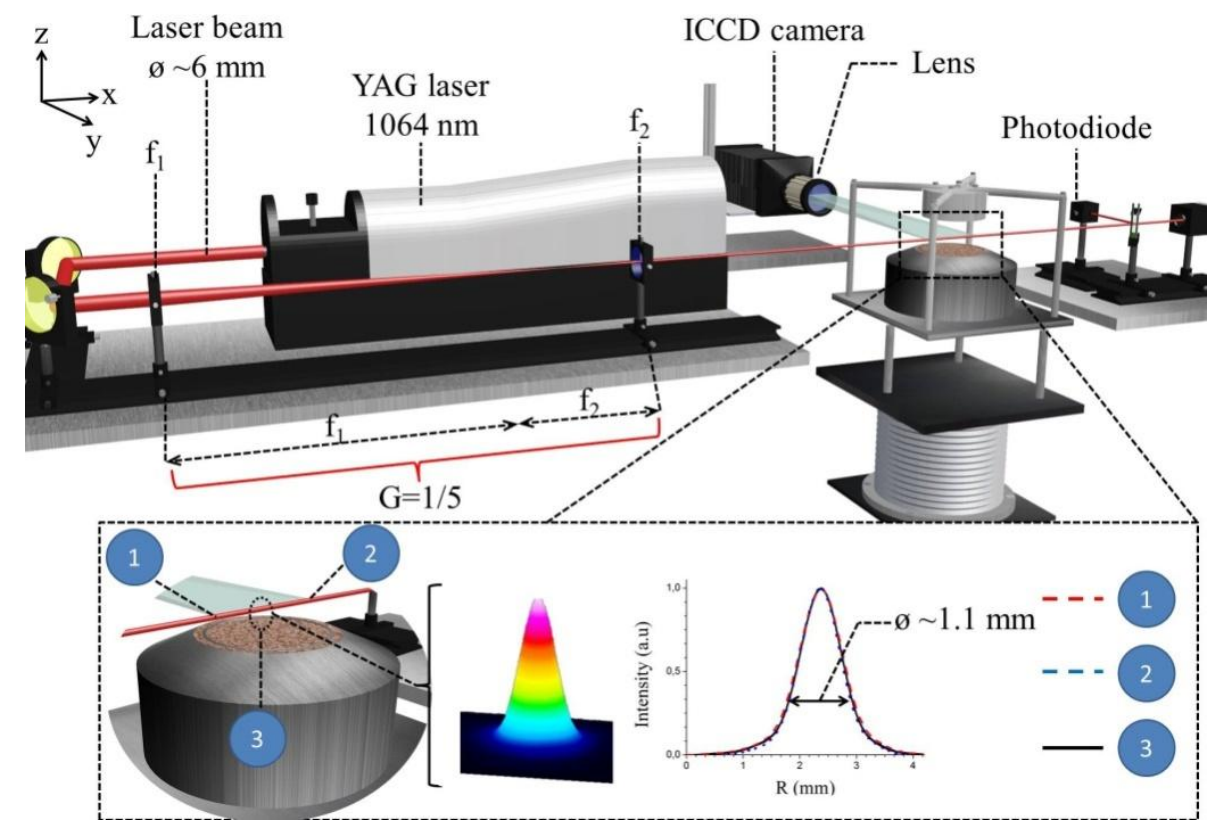

Fig. 1 Schematic representation of the LII experimental set-up for the determination of the relative radial soot distribution. The laser pulse radial profiles measured at position 1, 2 and 3 are shown in the bottom figure. These profiles were obtained based on the measured laser energy distributions, illustrated for position 3.

The radial LII profiles obtained by the 1D-LII imaging set-up shown in this work are corrected for background flame emissions. They have been recorded at different HABs in both Flame1.95 and Flame1.75 with the laser fluence set at $0.35 \mathrm{~J} / \mathrm{cm}^{2}$ to reach the plateau region. Figure 2 shows the relative radial LII profiles at different HABs in both flames. It reveals highly non-uniform radial soot distributions at a given $H A B$ as previously shown in $[40,41]$. The feature of non-uniform radial distribution is more pronounced in Flame1.75, Fig. 2 (b). It is worth pointing out that the signal-tonoise ratio decreases significantly with decreasing $\mathrm{HAB}$ in Flame1.75 due to the dramatic decrease of $f_{\mathrm{v}}$. In this study, the axial LII profiles measured by the PMTs were obtained by integrating at each HAB the LII signals over the $19 \mathrm{~mm}^{3}$ collection volume, whose width $(7.2 \mathrm{~mm})$ along the laser axis $(x)$ is indicated as the red arrows in Fig. 2. 

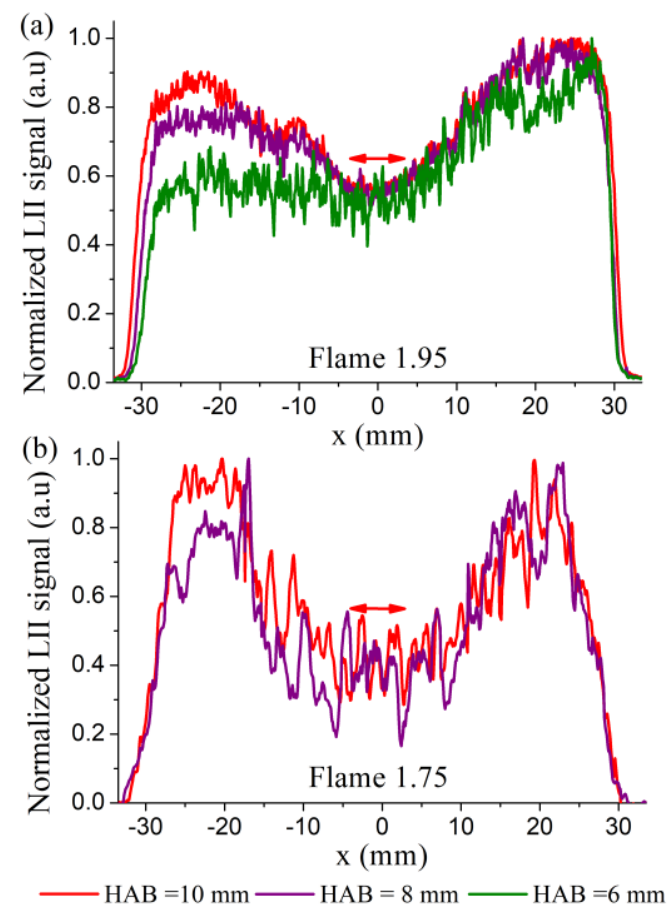

Fig. 2 Distributions of the normalized radial LII signal as a function of HAB in Flame1.95 (a) and Flame1.75 (b). The red arrows delimit the width $(7.2 \mathrm{~mm}$ ) of the LII collection volume along the laser axis $(x)$ as used in the detection scheme with the PMTs for axial measurements.

\subsection{CRDE measurements}

CRDE is a very sensitive technique well suited for measuring soot extinction at very low concentrations $[38,39,42,43]$. Note that the high spatial resolution laser cavity extinction technique recently developed by Tian et al. [10] does not offer the required sensitivity for the present study. The CRDE principle consists in injecting a laser beam in a resonant optical cavity and to follow the evolution of the transmitted light as a function of time.

The CRDE setup is shown schematically in Fig. 3 . The sooting flame is placed inside the cavity. The laser beam is shaped to match the TEM 00 transverse mode of the cavity. The CRDE cavity consists of two identical $25 \mathrm{~mm}$ diameter plano-concave mirrors (radius of curvature: $25 \mathrm{~cm}$, separated by $\mathrm{d}=$ $40 \mathrm{~cm}$, coated to achieve a high reflectivity of $\mathrm{R}=99.96 \%$ at $1064 \mathrm{~nm}$ ). The beam waist diameter was 
estimated to be around $300 \mu \mathrm{m}$ and nearly constant along the flame diameter. The laser fluence within the cavity is very low at around $6.10^{-5} \mathrm{~J} \cdot \mathrm{cm}^{-2}$, which prevents soot particles from laser-heating and photochemical effects. The light transmitted by the second mirror is collected by a photomultiplier (Hamamatsu, R5108). A longpass filter, which permits transmission of light with wavelengths above $850 \mathrm{~nm}$, is placed in front of the PMT to suppress the background emission from the flame. The signal is recorded by an oscilloscope (Lecroy HDO4000, 12-bit, 1GHz, 1.25 GS/s). The experimental signal is exponentially fitted to extract the pulse decay time $\tau$. In the absence of soot, the losses of light transmission are due to the mirrors and to potential gaseous species absorption. The decay time was found unchanged in an empty cavity or in the cavity containing a soot-free premixed flame at an equivalence ratio of 1.6 , indicating that the contribution of light attenuation by gaseous species at $1064 \mathrm{~nm}$ is negligible. Under these conditions, the pulse decay time $\tau_{0}$ is given by Eq. (1):

$\tau_{0}=\frac{d}{c} \frac{1}{(1-R)}$

In the presence of soot, the pulse decay time $\tau_{\text {soot }}$ is reduced, due to the additional losses from the soot (Eq. (2)):

$\tau_{\text {soot }}=\frac{d}{c} \frac{1}{(1-R)+\int{ }_{l_{S}} K_{\lambda}^{\text {ext }} d x}=\frac{d}{c} L^{-1}$

where $L$ is the total loss per pass in the cavity, $d$ the length of the cavity, $c$ the speed of light, $R$ the reflection coefficient of the mirrors, $l_{s}$ the flame diameter determined at $1 / \mathrm{e}$ of the normalized LII profile (Fig. 2) and $K_{\lambda}^{\text {ext }}$ the extinction coefficient of soot at $1064 \mathrm{~nm}$.

By rearranging the above expressions of $\tau_{0}$ and $\tau_{\text {soot }}$, it is possible to directly determine the mean soot extinction coefficient across the flame diameter as follows

$$
\int_{l_{s}} K_{\lambda}^{\text {ext }} d x=\overline{K_{\lambda}^{e x t}} l_{s}=\frac{d}{c}\left(\frac{1}{\tau_{\text {soot }}}-\frac{1}{\tau_{0}}\right)
$$

In the flames considered in this study, the soot particles are much smaller than the laser wavelength of $1064 \mathrm{~nm}$. Therefore, the light extinction is dominated by absorption, i.e., the contribution of scattering can be confidently neglected. 


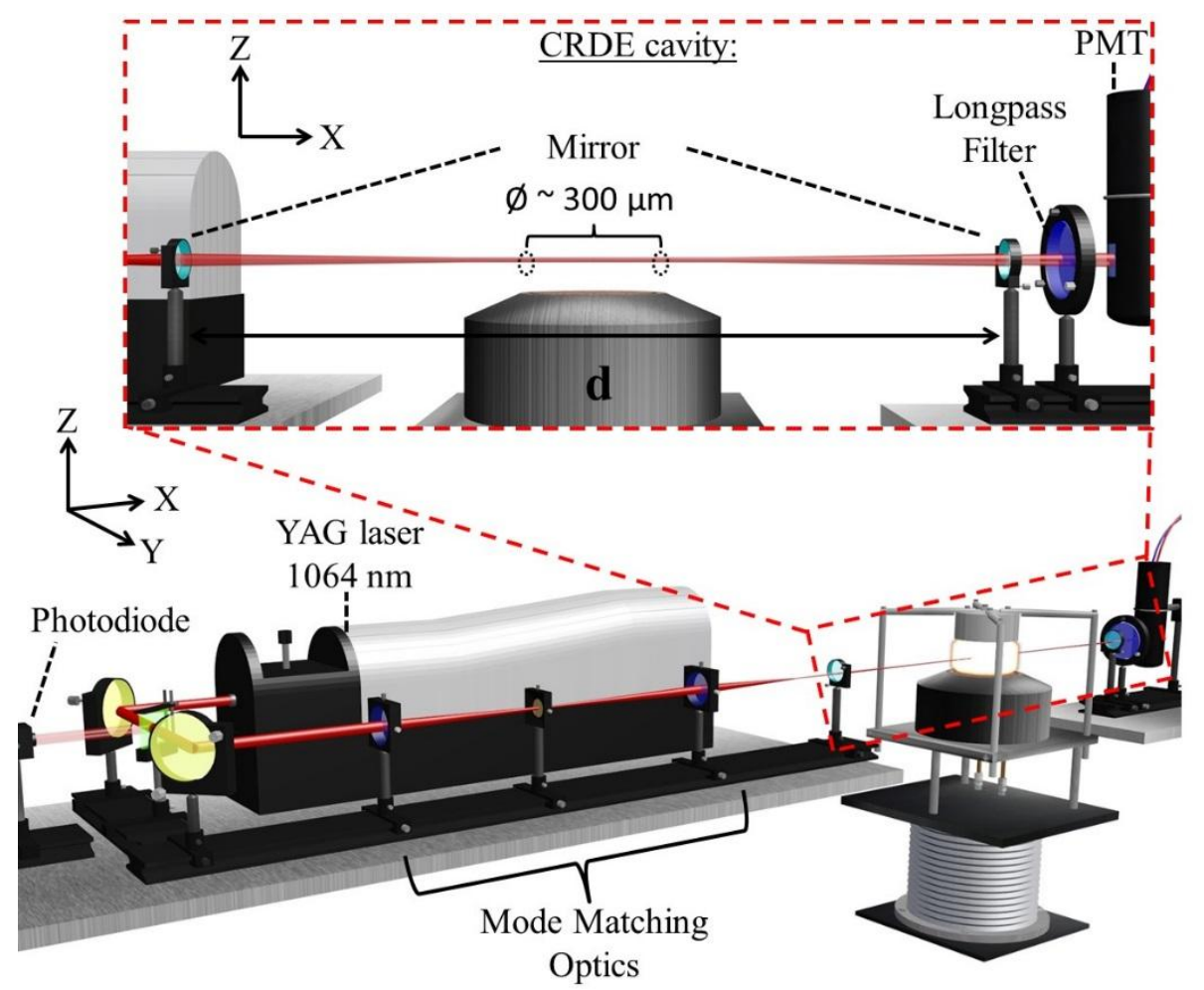

Fig. 3 Schematic representation of the CRDE experimental setup.

\section{Numerical and analysis methods}

Under the irradiation of the incident laser pulse, the soot particles undergo temperature rise during the laser pulse and then temperature decay after, or even during, the laser pulse, depending on the laser fluence and particle size. The unsteady energy equation of a primary soot particle of diameter $d_{p}$ is described by the following equation [20]

$\rho_{s} c_{s} \frac{\pi}{6} d_{p}^{3} \frac{d T}{d t}=\dot{q}_{a b s}-\dot{q}_{c o n d .}-\dot{q}_{s u b l .}-\dot{q}_{r a d}$

The left-hand side represents the change rate in the particle internal energy. The right-hand side terms of Eq. (4) represent the rate of energy gain by laser energy absorption and the rates of energy loss by conduction to the surrounding gases, soot sublimation, and thermal radiation (incandescence), respectively. Under the irradiation of a high fluence laser pulse, the soot particles in the detection volume can undergo significant sublimation. In this case, it is necessary to include the mass conservation equation of a primary soot particle expressed as 
$\frac{d M}{d t}=\frac{1}{2} \rho_{s} \pi d_{P}^{2} \frac{d d_{p}}{d t}=-\pi d_{p}^{2} N_{v} \frac{M_{v}}{N_{A}}$

In Eq. (5), $M$ is the mass of the soot particle, $M_{v}$ is the mean molecular weight of the sublimed carbon species, $N_{v}$ and $N_{A}$ are the molecular flux of sublimed carbon species and Avogadro constant, respectively. Further details of the terms in the energy equation Eq. (4) and the sublimation model can be found in [44] and the references cited therein. Other physical and chemical processes [45], such as annealing of the particles, non-thermal photodesorption of carbon clusters and soot oxidation were neglected mainly due to the lack of reasonably established models or model parameters to simulate these processes and/or uncertain conclusions with regard to their importance in LII [46].

In the present study, the primary soot particles are sufficiently small (less than $16 \mathrm{~nm}$ ) so that it is valid to use the Rayleigh expression for the particle absorption cross section. Consequently, the total thermal emission intensity generated from soot particles in the LII detection volume can be expressed as

$S_{L I I}\left(\lambda_{e m}, z\right)=E\left(m_{\lambda_{e m}, z}\right) \frac{48 \pi^{2} h c^{2}}{\lambda_{e m}^{6}}\left[\exp \left(\frac{h c}{\lambda_{e m} k_{b} T(z)}\right)\right]^{-1} f_{v}(z)$

where $\mathrm{E}\left(\mathrm{m}_{\lambda_{\mathrm{em}, \mathrm{z}}}\right)$ is the soot absorption function at the detection wavelength $\lambda_{\mathrm{em}} z$ is the axial location along the flame centerline, i.e., $z=H A B$, and $T(z)$ is the soot temperature inferred from the ratio of the LII signals. It is understood that the LII signal $S_{L I I}$, soot temperature $T$, and soot volume fraction $f_{v}$ in Eq. (6) all vary with time $t$. However, the time dependence of these quantities in Eq. (6) is not explicitly expressed since it is used in this study to infer $f_{\mathrm{v}}(\mathrm{z})$ at the moment of the peak LII signals. It is important to point out that the inferred $f_{\mathrm{v}}(\mathrm{z})$ at the peak LII signals can be less than the unperturbed soot concentration due to sublimation loss at high laser fluences. The effect of soot mass loss due to sublimation at different $\mathrm{HAB}$ on the LII measured $f_{\mathrm{v}}$ will be evaluated using the LII model described above.

In this study, the measurements of axial LII profiles were performed by collecting the incandescence signals at $\lambda_{\mathrm{em}}=532 \mathrm{~nm}$. The prompt-LII signal measured at $\mathrm{HAB}=\mathrm{z}$ in flame $\phi_{\mathrm{i}}$ can be related to the 
soot temperature $\mathrm{T}(\mathrm{z})$ and soot volume fraction $f_{\mathrm{v}}(\mathrm{z})$ in the detection volume through Eq. (6). Thus, we have

$S_{L I I}(z) \propto \frac{E\left(m_{\lambda_{e m}, z}\right)}{\lambda_{e m}} I_{b b}\left(\lambda_{e m}, T(z)\right) f_{v}(z)$

where $I_{b b}$ is the Planck blackbody spectral radiation intensity

$$
I_{b b}\left(\lambda_{e m}, T\right)=\frac{2 \pi h c^{2}}{\lambda_{e m}{ }^{5}}\left[\exp \left(\frac{h c}{\lambda_{e m} k_{b} T}\right)-1\right]^{-1}
$$

The soot temperature $\mathrm{T}$ is determined by the ratio of the LII signals collected at the two spectral bands as:

$T=\frac{h c}{k_{b}}\left(\frac{1}{\lambda_{2}}-\frac{1}{\lambda_{1}}\right)\left[\ln \left(C^{-1} \frac{E\left(m_{\lambda_{2}}\right)}{E\left(m_{\lambda_{1}}\right)}\left(\frac{\lambda_{1}}{\lambda_{2}}\right)^{6} R\right)\right]^{-1}$

where $\mathrm{R}$ is the ratio of the LII signals collected at $\lambda_{1}=532$ and $\lambda_{2}=650 \mathrm{~nm}$ [26] and $C$ is the calibration factor of the detection setup. The choice of $E(m)$ values at 532 and $650 \mathrm{~nm}$ impacts the soot temperature, and consequently $I_{b b}$ and the relationship between $S_{\mathrm{LI}}$ and $f_{\mathrm{V}}$ [47]. To minimize the uncertainty of soot temperature on the measured $f_{\mathrm{v}}$ in the conventional implementation of the LII technique, it is required to heat the soot particles to sublimation temperatures by using a laser fluence in the plateau regime of the fluence curve [48]. Although this strategy has also been selected in this study, it is only for the purpose of maximizing the signal-to-noise ratio, especially at low HAB.

Concerning the $E(m)$ variation along $\mathrm{HAB}$, it is often considered as constant, though several studies have shown that $E(m)$ increases with $\mathrm{HAB}$ as soot becomes more mature $[11-13,18]$. To obtain accurate quantitative axial profiles of $f_{\mathrm{V}}$, it is necessary to take into account the variation of $E(m)$ with $\mathrm{HAB}$, i.e., the level of maturity. In this study, we developed two novel approaches presented later to evaluate the variation of $E(m)$ with $\mathrm{HAB}$ and the spectral dependence of $E(m)$ in the spectral range of 532 and $1064 \mathrm{~nm}$. 


\section{Results}

\subsection{In-situ evaluation of the variation of thermal-optical parameters with HAB}

Before soot particles reach their sublimation temperature, the rate of temperature increase during the laser pulse is mainly controlled by the laser energy absorption rate as well as the product of $\rho_{s} c_{s}$ $[20,49]$. Thus, in the low laser fluence regime where the peak soot particle temperature is below about $3700 \mathrm{~K}$ to induce negligible soot sublimation, the laser energy absorbed by the particle is nearly fully utilized to increase the particle temperature. Consequently, the particle energy equation takes a very simple form and establishes a relationship between the optical-thermal properties of the soot particle, the laser properties, and the peak soot particle temperature. Such relationship was first introduced by Snelling et al. [49] for $E(m)$ determination of soot and more recently adopted by Michelsen et al. [50], López-Yglesias et al. [25] and Johansson et al. [24]. From Eq. (4), it can be deduced in this case that:

$\frac{1}{6} \pi d_{p}^{3} \rho_{s} c_{s} \frac{d T}{d t} \approx C_{a} F q(t)=\frac{\pi^{2} d_{p}^{3} E\left(m_{\lambda_{\text {laser }}}\right)}{\lambda_{\text {laser }}} F q(t)$

This is because the particle heat conduction loss rate $\dot{q}_{c o n d}$. is in general fairly low (except at elevated pressures) and can be neglected in comparison to the particle laser energy absorption rate $\dot{q}_{a b s}$ from the onset till nearly the end of the laser pulse. In Eq. (10), $C_{a}$ is the primary particle absorption cross section, $\mathrm{F}$ the laser fluence and $\mathrm{q}(\mathrm{t})$ the normalized laser power temporal profile (its integration over the laser pulse yields unity laser fluence). The integration of Eq. (10) over the laser pulse from 0 to $t=$ $t_{p}$, at which the temporal LII signal (or the soot temperature) peaks, gives:

$\Delta T=T\left(t_{p}\right)-T_{g}=\frac{6 \pi}{\lambda_{\text {laser }}} E\left(m_{\lambda_{\text {laser }}}\right) \int_{0}^{t_{p}} \frac{F q(t)}{\rho_{s} c_{s}} d t$

It is worth pointing out that for a given primary particle diameter $t_{p}$ remains constant, i.e., independent of the laser fluence, in the low fluence regime. However, it was found from numerical modelling that $t_{\mathrm{p}}$ increases slightly as the primary particle diameter becomes larger. Such a slight shift in $t_{\mathrm{p}}$ around the end of the laser pulse has a negligible influence on either the peak soot 
temperature or the integration of $q(t)$ with respect to time, which is essentially equal to unity. To take the product $\rho_{S} c_{S}$ out of the integral, it is necessary to assume that it remains constant during the laser pulse, i.e., it does not change with soot temperature. The following two scenarios are considered for this purpose. In the first scenario, taking the temperature dependent soot heat capacity expression given in the model by Liu [20], it is found that $c_{S}$ increases only slightly by $3.1 \%$ from 2400 to $3500 \mathrm{~K}$, i.e., the relevant range of soot temperature to the low fluence regime in this study. Therefore, it is a good approximation to assume that $c_{S}$ is independent of temperature in low fluence LII. If we also make the assumption that the soot density is constant, then the product $\rho_{S} c_{S}$ is independent of temperature. A similar argument for the constancy of $\rho_{s} c_{S}$ has also been made recently by López-Yglesias et al. [25]. It should be noticed that the specific choice of the temperature dependent expression of $c_{s}$ has no influence on the results given in Table 1 presented later, as long as $c_{s}$ is assumed constant over the temperature range of interest. In the second scenario, following the recent study by Johansson et al. [24] on graphite, we assume the product $\rho_{s} c_{s}$ remains nearly constant during particle heating (not just in the low fluence regime).

Under either approach, Eq. (11) becomes

$\Delta T=T\left(t_{p}\right)-T_{g}=6 \pi \frac{F}{\lambda_{\text {laser }}} \frac{E\left(m_{\lambda_{\text {laser }}}\right)}{\rho_{s} c_{s}}$

Eq. (12) shows that the peak temperature increase $(\Delta T)$ of a soot particle from the local flame temperature $T_{g}$ under the irradiation of the laser pulse with a low fluence $\mathrm{F}$ is directly proportional to both the soot parameters $E\left(m_{\lambda_{\text {laser }}}\right) / \rho_{s} c_{s}$ and the laser property $\left(\mathrm{F} / \lambda_{\text {laser }}\right)$, regardless of the soot particle size as long as it is sufficiently small compared to the laser wavelength to be in the Rayleigh regime. It is noticed that $E\left(m_{\lambda_{\text {laser }}}\right) / \rho_{s} c_{s}$ represents a combination of the thermal and optical properties of the soot particles in the LII detection volume. Although similar expressions as Eq. (12) are found in $[24,25,49,50]$, none of these works has attempted to study experimentally the behavior of $\Delta T$ with the laser fluence, as done below. 
The evolution of $\Delta T$, with $T\left(t_{p}\right)$ obtained by $2 \mathrm{C}$-LII at the temporal peak of the LII signals along with the assumption that soot $E(m)$ is independent of wavelength in the visible and near infrared spectra (as validated in Section 4.2.3.2) and $T_{g}$ provided by NO-LIF thermometry [26], is plotted as a function of the laser fluence $F$ at $1064 \mathrm{~nm}$ at different $\mathrm{HAB}$ in Flame1.95 and at $\mathrm{HAB}=10 \mathrm{~mm}$ in Flame1.75 in Fig. 4. The gas temperatures obtained from NO-LIF thermometry and detailed in [26] are 1566, 1620, $1673 \mathrm{~K}$ at $\mathrm{HAB}=10,7,5 \mathrm{~mm}$, respectively, in Flame1.95 and $1570 \mathrm{~K}$ at $\mathrm{HAB}=10 \mathrm{~mm}$ in Flame1.75 with an accuracy of $\pm 80 \mathrm{~K}$. Globally, the temperature increase in each flame condition behaves similarly. In the low fluence regime (corresponding to $\Delta \mathrm{T}$ below $2200 \mathrm{~K}$ in our flame conditions), $\Delta T$ in Flame1.95 is higher for more mature soot $(\mathrm{HAB}=10$ and $7 \mathrm{~mm}$ ) than for young soot ( $\mathrm{HAB}=5 \mathrm{~mm})$, in a consistent way with the literature $[11-13,18]$. The temperature curves obtained for different soot maturities are overall similar (Fig. 4). Based on Eq. (12), the similarity of plots shown in Fig. 4 indicates that these soot particles have similar thermal-optical properties. The signal-to-noise ratio of prompt-LII signals was too low to reliably determine soot temperature at fluences below $0.2 \mathrm{~J} / \mathrm{cm}^{2}$ in Fig. 4 at $\mathrm{HAB}=10 \mathrm{~mm}$ in Flame1.75. However, it is noted that by using spectrally-resolved LII signals, temporally integrated over 10 ns starting from the peak of laser pulse as used in our recent work [26], soot temperature measurement was found possible down to $0.13 \mathrm{~J} / \mathrm{cm}^{2}$. Since the method developed in this paper is applicable at the temporal LII peak only, $\Delta \mathrm{T}$ obtained from the two-color prompt LII measurements was used in the following analysis, even though this method appears less sensitive than the previous one.

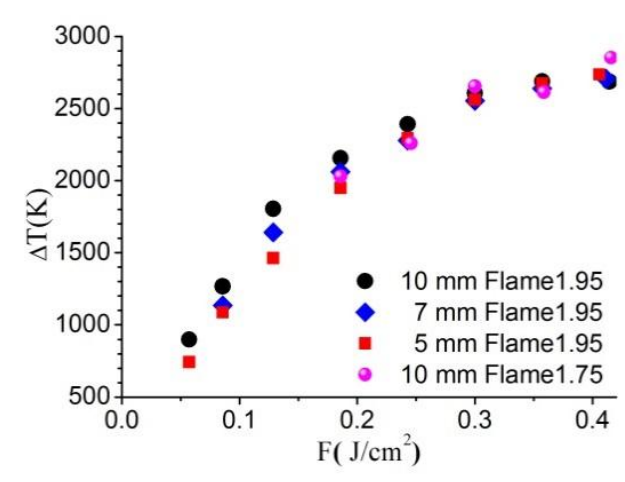


Fig. $4 \Delta T$ as a function of laser fluence $F$ at $1064 \mathrm{~nm}$.

Equation (12) is the basis of a novel method presented here, allowing in-situ determination of the relative variation of $\Lambda=E\left(m_{\lambda_{\text {laser }}}\right) / \rho_{s} c_{s}$ with HAB in flames as described below. Considering two different soot particles (P1) and (P2) with $\Lambda_{1}$ and $\Lambda_{2}$, respectively, that are heated by a laser fluence $\mathrm{F}$, the ratio of their temperature increases is then equal to the ratio of $\Lambda$ as:

$\frac{T_{2}-T_{g 2}}{T_{1}-T_{g 1}}=\frac{\Lambda_{2}}{\Lambda_{1}}$

where $T_{1}$ and $T_{2}$ are the peak temperatures reached by $P 1$ and $P 2$ respectively from their initial temperatures $T_{g 1}$ and $T_{g 2}$.

It can be easily shown that when particle $\mathrm{P} 2$ is heated by a fluence $\mathrm{G}=\mathrm{F} \times \Lambda_{1} / \Lambda_{2}$, it will reach the same temperature increase as particle $P 1$ heated by fluence $F$, i.e.,

$T_{2}-T_{g 2}=\frac{6 \pi}{\lambda_{\text {laser }}} \Lambda_{2} \int_{0}^{t_{p}} G q(t) d t=\frac{6 \pi}{\lambda_{\text {laser }}} \Lambda_{2} \int_{0}^{t_{p}}\left(F \cdot \frac{\Lambda_{1}}{\Lambda_{2}}\right) q(t) d t=\frac{6 \pi}{\lambda_{\text {laser }}} \Lambda_{1} \int_{0}^{t_{p}} F q(t) d t=T_{1}-T_{g 1}$ Eq. (14)

Eq. (14) suggests that it is possible to establish the relationship between $\Lambda_{1}$ and $\Lambda_{2}$ by scaling the temperature increase curve of particle P2 along the horizontal fluence axis by a factor $\Lambda_{2} / \Lambda_{1}$, to rescale the laser fluence so that the scaled curve coincides with that of particle P1 in the low fluence regime. Application of this strategy to Fig. 4 leads to Fig. 5 with particle P1 being the incandescent soot at $H A B=5 \mathrm{~mm}$ in Flame1.95. The required scaling factors $\Lambda_{2} / \Lambda_{1}$ at different $H A B s$ in Flame1.95 and at $\mathrm{HAB}=10 \mathrm{~mm}$ in Flame1.75 to make these temperature increase curves coincide with the curve of P1 are indicated in the figure legend. Due to the absence of measured soot temperatures below $0.2 \mathrm{~J} / \mathrm{cm}^{2}$ in Flame1.75, the scaling factor $\Lambda_{2} / \Lambda_{1}=1$ at $\mathrm{HAB}=10 \mathrm{~mm}$ in Flame1.75 is not based on the measured soot temperature increases at low fluences, but assumed based on the very similar LII signals, soot particle sizes, and the local gas temperatures between $\mathrm{HAB}=10 \mathrm{~mm}$ in Flame1.75 and $\mathrm{HAB}=5 \mathrm{~mm}$ in Flame1.95 [26]. In addition, the unity scaling factor at $\mathrm{HAB}=10 \mathrm{~mm}$ in Flame1.75 is also backed by the good agreement in soot temperatures obtained previously in [26] using 
spectrally-resolved LII signals, temporally integrated over $10 \mathrm{~ns}$ in Flame1.95 (5 mm) and Flame1.75 $(10 \mathrm{~mm})$ over a large range of fluence down to $0.13 \mathrm{~J} / \mathrm{cm}^{2}$.

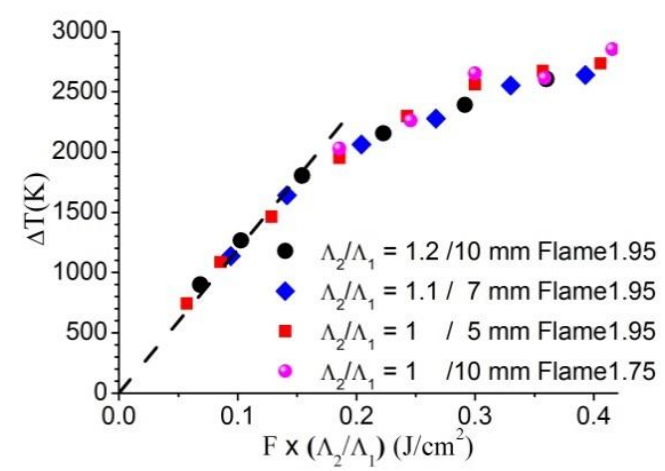

Fig. $5 \Delta$ Tas a function of $F \times \Lambda_{2} / \Lambda_{1}$ (see text) in Flame1.95 and Flame 1.75. The legend represents the adjusted value of $\Lambda_{2} / \Lambda_{1}$.

Since this approach is valid only in the low laser fluence regime, the scaling factor is determined by optimizing the fitting of the temperature increase curves with respect to that at $\mathrm{HAB}=5 \mathrm{~mm}$ in Flame1.95 in the low laser fluence regime, i.e., at fluences below $0.15 \mathrm{~J} / \mathrm{cm}^{2}$ under the conditions of this study.

It is noticed that $\Delta T$ follows a linear variation with $F \times \Lambda_{2} / \Lambda_{1}$ as expected from Eq. (12) for $F<0.15$ $\mathrm{J} / \mathrm{cm}^{2}$. At higher fluences, sublimation becomes significant as previously shown by Olofsson et al [18] and the above analysis is no longer valid. Based on the values of $\Lambda_{2} / \Lambda_{1}$ determined using the fluence scaling approach applied to the soot temperature increase curves, the value of $E\left(m_{1064}\right)$ at different HABs in Flame1.95 and Flame1.75 can be related to the $E\left(m_{1064}\right)$ value of the reference soot (particle $\mathrm{P} 1$ at $\mathrm{HAB}=5 \mathrm{~mm}$ in Flame1.95), provided that the product of $\rho_{\mathrm{s}} \mathrm{c}_{\mathrm{s}}$ is known.

Using the fluence scaling procedure described above applied to the temperature curves (conversion from Fig. 4 to Fig. 5), we could determine the values of $E\left(m_{1064}\right)$ in Flame1.75 and Flame1.95 for different $H A B s$ with respect to the reference values. The reference values at $H A B=5 \mathrm{~mm}$ in Flame1.95 were determined by LII modeling [26] and found equal to $E\left(m_{1064}\right)=0.25 \pm 0.02$ based on the choice of $\rho_{s}=1.3 \mathrm{~g} / \mathrm{cm}^{3}$ for the smallest incandescent soot particles. For consistency, the 
same value for soot density is chosen here, even if no final consensus on this choice exists currently in the literature.

The fluence scaling approach applied to the temperature curves described above shares some similarity with the recent work of Johansson et al. [24]. Indeed Eq. (12) in this work is similar to Eq. (7) in [24], since both are the energy balance equation for a single primary particle in the low laser fluence regime. However, Johansson et al. considered the deviation of the absorption cross section from the $\lambda^{-1}$ dependence by introducing a dispersion exponent $\alpha$ into the expression of $E(m)$. $\alpha$ is determined from the scaling of the peak LII normalized fluence curves at two wavelengths (532 and $1064 \mathrm{~nm}$ ). The energy balance equation of a primary particle at the end of laser pulse of low fluence then leads to $\rho c_{s}\left(T_{\max }-T_{g}\right) \lambda_{\text {laser }}{ }^{\alpha-1}=\beta F(\lambda)$, where $\mathrm{T}_{\max }$ denotes the soot temperature associated with the normalized peak-LII signal at fluence $F(\lambda)$ and $\beta$ is an empirical scaling factor linked to $E(m)$. Following the approach developed in [37], the peak-LII signal in [24] is defined as a "proxy" for maximum soot temperature. $\mathrm{T}_{\max }$ is deduced from this normalized LII signal at each fluence. Therefore, plotting the left-hand side of the above equation as function of $F(\lambda)$ is a measure of $\beta$ and thus of $\mathrm{E}(\mathrm{m})$ assuming a constant behavior of $\rho c_{s}$.

There are several important differences between our work and that of Johansson et al. First, we plot exactly $\Delta T$ as function of the laser fluence and as set out the expression of Eq. (14), valid only in the low fluence regime, we obtain one unique straight-line $\Delta T$ as function of $\Lambda F$. In [24] $\Delta T$ is not directly measured but is deduced from the normalized LII fluence curve. In their procedure it is assumed that all particles reach the same temperature during sublimation. The second main difference is that their method needs to obtain LII signals in the plateau region. Although the plateau region is generally reached for mature soot, a full plateau is not reached for young soot particles in premixed flames $[28,29]$ or diffusion flames [24]. In summary, both the fluence scaling method applied to the temperature curves (this study) and that applied to the normalized LII curves [24] can be applied to recover $\Lambda=E\left(m_{\lambda_{\text {laser }}}\right) / \rho_{s} c_{s}$. However, the present scaling method offers the advantages of 
conducting measurements only in the low-fluence regime and without making the assumptions that soot particles of different maturities reach the same temperature in the plateau region. In addition, in the context of this work involving very small soot particles, only the present method allows to reach this objective because of the absence of a full plateau region in the fluence curve.

It is useful to point out that the soot density reported in this study was inferred under the assumption that the specific heat of soot remains unchanged with respect to the level of soot maturity. This assumption is necessary since the specific heat of immature soot is currently unavailable. In Flame1.95 at $\mathrm{HAB}=10 \mathrm{~mm}$, the soot particles are considered fairly mature [26]. Under the first assumption, by considering $\Lambda_{2} / \Lambda_{1}=1.2 \pm 0.10$ (Fig. 5) and the widely used value of mature soot density of $1.8 \mathrm{~g} / \mathrm{cm}^{3}$, one obtains $E\left(m_{1064}\right)=0.41 \pm 0.06$ at $\mathrm{HAB}=10 \mathrm{~mm}$ in Flame1.95. This value is consistent with values reported for mature soot [11-13]. Due to a lack of better information about how $E\left(m_{1064}\right)$ or $\rho$ varies with HAB in Flame1.95, it is assumed here that the soot density varies linearly with HAB. Based on this assumption and using $\Lambda_{2} / \Lambda_{1}=1.1$ (Fig. 5), we obtained $\rho_{\mathrm{s}}=1.5 \mathrm{~g} / \mathrm{cm}^{3}$ and $E\left(m_{1064}\right)=0.32$ at $\mathrm{HAB}=7 \mathrm{~mm}$ in Flame1.95. In the nucleation flame Flame1.75, despite the fact that the signal-to-noise ratio was too low to measure an accurate soot temperature using two-color prompt-LII for laser fluences lower than $0.2 \mathrm{~J} / \mathrm{cm}^{2}$, we can assume the scaling factor remains equal to 1 based on our previous study [26], as discussed above. We have assumed here that $E\left(m_{1064}\right)$ and $\rho_{\mathrm{s}}$ of soot at different $\mathrm{HABs}$ in the nucleation flame equal to those of the smallest incandescent soot at $\mathrm{HAB}=5 \mathrm{~mm}$ in Flame1.95. The values of $E\left(m_{1064}\right)$ and $\rho_{\mathrm{s}}$ at different $\mathrm{HABs}$ in the two flames are summarized in Table 1.

\begin{tabular}{|c|c|c|c|c|}
\cline { 2 - 5 } \multicolumn{1}{c|}{} & \multicolumn{2}{c|}{ Flame1.95 } & \multicolumn{2}{c|}{ Flame1.75 } \\
\hline HAB $(\mathrm{mm})$ & $E\left(m_{1064}\right)$ & $\rho_{s}$ & $E\left(m_{1064}\right)$ & $\rho_{s}$ \\
\hline 10 & $0.41^{\mathrm{c}}$ & $1.80^{\mathrm{a}}$ & $0.25^{\mathrm{c}}$ & $\mathbf{1 . 3 0}^{\mathrm{b}}$ \\
\hline 7 & $0.32^{\mathrm{c}}$ & $1.50^{\mathrm{d}}$ & $0.25^{\mathrm{e}}$ & $1.30^{\mathrm{e}}$ \\
\hline 5 & $\mathbf{0 . 2 5 ^ { \mathrm { b } }}$ & $\mathbf{1 . 3 0 ^ { \mathrm { b } }}$ & $\mathbf{0 . 2 5 ^ { \mathrm { e } }}$ & $\mathbf{1 . 3 0 ^ { \mathrm { e } }}$ \\
\hline
\end{tabular}

\footnotetext{
${ }^{a}$ Literature [49]

${ }^{b}$ Reference value extracted from [26]

${ }^{c}$ Values obtained from the scaling factor (scenario 1)

${ }^{\mathrm{d}}$ linear interpolation between 5 and $10 \mathrm{~mm}$
} 
${ }^{\mathrm{e}}$ Setting value (see text)

Table $1 E\left(m_{1064}\right)$ and $\rho_{s}$ in Flame1.95 and Flame1.75

In the second scenario to derive Eq. (12) from Eq. (11) discussed above, $\rho_{s} c_{s}$ is considered constant regardless of soot maturity. The fluence scaling approach applied to the soot temperature increase curves allows to estimate the variation of $E\left(m_{1064}\right)$ at different HABs in Flame1.95 (it remains constant in Flame1.75). Using the scaling factors at $\mathrm{HAB}=7$ and $10 \mathrm{~mm}$ (Fig. 5) and $E\left(m_{1064}\right)=0.25$ at $\mathrm{HAB}=5 \mathrm{~mm}$ in Flame1.95, the corresponding values of $E\left(m_{1064}\right)$ were found to be equal to 0.28 and 0.3 , which are respectively $11 \%$ and $27 \%$ less than those inferred from the first scenario.

Regardless of the selected scenario with respect to product $\rho_{s} c_{s}$, the fluence scaling approach applied to the soot temperature increase curves proposed above allows the in situ determination of the relative variation of $E\left(m_{1064}\right) / \rho_{s} c_{s}$ from which $E\left(m_{1064}\right)$ can be estimated. The values of $E\left(m_{1064}\right)$ determined from this approach are sensitive to the knowledge of the product of soot density and soot specific heat, which certainly deserves further work [51]. It must be noticed that the lack of accurate knowledge of soot density and soot specific heat restrains the accuracy of LII models and quantitative interpretation of LII signal in the literature. It is also important to point out that although only the ratio $E\left(m_{1064}\right) / \rho_{S} c_{S}$ is required to model the soot particle temperature rise rate during laser heating, the product $\rho_{\mathrm{s}} \mathrm{c}_{\mathrm{s}}$ is needed during the particle cooling and $E\left(m_{\lambda \mathrm{em}}\right)$ is important in the quantification of soot volume fraction. Therefore, in LII modeling and data processing it is necessary to have accurate knowledge of both $E(m)$ and the product of $\rho_{s} c_{s}$.

$E\left(m_{1064}\right)$ gradually increases in Flame1.95 from 0.25 at $\mathrm{HAB}=5 \mathrm{~mm}$, to 0.32 at $7 \mathrm{~mm}$ and 0.41 at 10 $\mathrm{mm}$ (Table 1). These values are in the range of available data at $1064 \mathrm{~nm}$ in the literature. It should be emphasized that the $E\left(m_{1064}\right)$ values given in Table 1 are subject to the assumptions made to the soot density at different degrees of soot maturity and the soot specific heat is always equal to that of graphite. 


\subsection{Procedure to obtain absolute $f_{\mathrm{v}}$ profiles}

\subsubsection{LII profiles}

The relative axial LII profiles have been measured in Flame1.95 and Flame1.75 following the procedure described in Section 2. These axial LII profiles have been obtained using $0.35 \mathrm{~J} / \mathrm{cm}^{2}$ to get a satisfying signal to noise ratio. The results are shown in Fig. 6 . It is evident that signals extend over a wide dynamic range of more than three orders of magnitude.

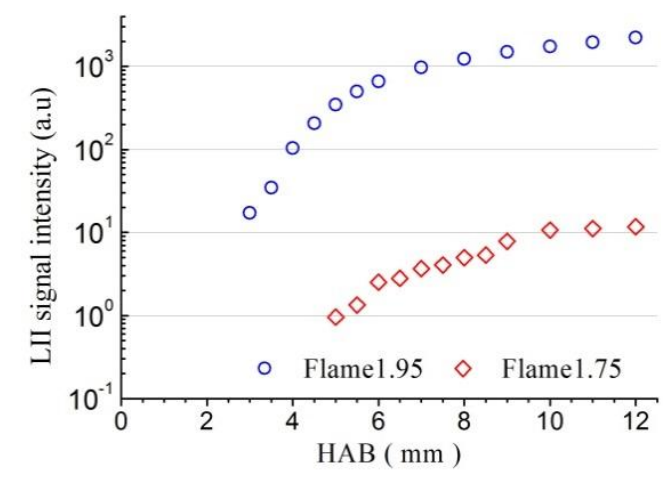

Fig. 6 Evolution of the raw LII signal as a function of the $H A B\left(0.35 \mathrm{~J} . \mathrm{cm}^{-2}\right)$.

Fig. 7 reports the variation of soot temperature T (calculated using Eq. (9) and assuming $\frac{E\left(m_{650}\right)}{E\left(m_{532}\right)}=1$ ) with $\mathrm{HAB}$ in both flames. The soot temperatures are displayed with an uncertainty of $\pm 4.4 \%$ for $H A B \geq 4 \mathrm{~mm}$ in Flame1.95 and $H A B \geq 6 \mathrm{~mm}$ in Flame1.75. The uncertainty is estimated to around $\pm 8 \%$ for lower HABs. This uncertainty is mainly caused by the error in the calibration factor $C$ (Eq. (9)), while the standard deviation on $R$ is very low $(<0.5 \%$ in Flame1.75 and $<0.1 \%$ in Flame1.95), except at low HAB where the signal to noise ratio deteriorates. These results show that T reaches a plateau with a mean value of about $4250 \mathrm{~K}$ in Flame1.95 and $4110 \mathrm{~K}$ in Flame1.75. 


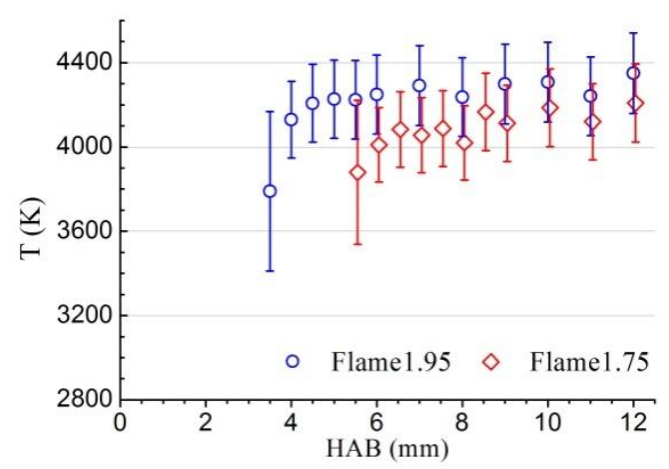

Fig. 7 Soot temperature $T$ measured considering $E\left(m_{1064}\right) / E\left(m_{532}\right)=1$ as function of $H A B(0.35$ J. $\left(\mathrm{cm}^{-2}\right)$.

\subsubsection{CRDE calibration}

The relative axial LII signals shown in Fig. 6 were converted to absolute soot volume fractions by calibration using the highly-sensitive CRDE measurements at $\mathrm{HAB}=10 \mathrm{~mm}$ in both flames.
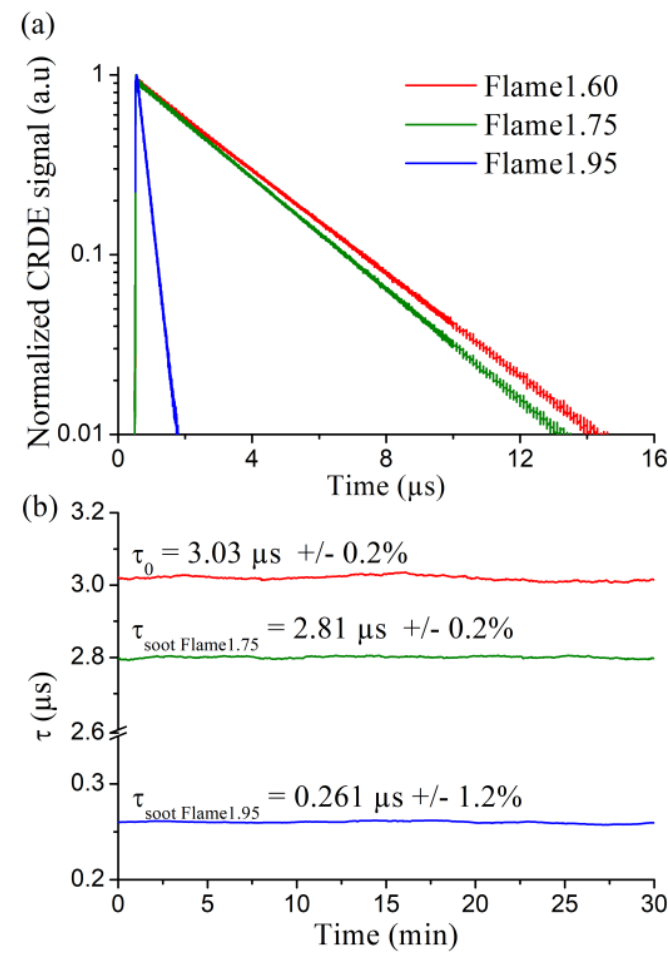

Fig. 8(a) displays the normalized CRDE signals in Flame1.95 and Flame1.75 (with soot) and in

Flame1.60 (without soot). It is clear from this figure that the decay time decreases with increasing the amount of soot in the flames. It is important to emphasize that the incandescent soot particles as small as 2 to $4 \mathrm{~nm}$ in Flame1.75 [26] are able to absorb radiation at $1064 \mathrm{~nm}$, in a consistent way 
to reveal the absorption property of the smallest incandescent soot with the present and recent LII
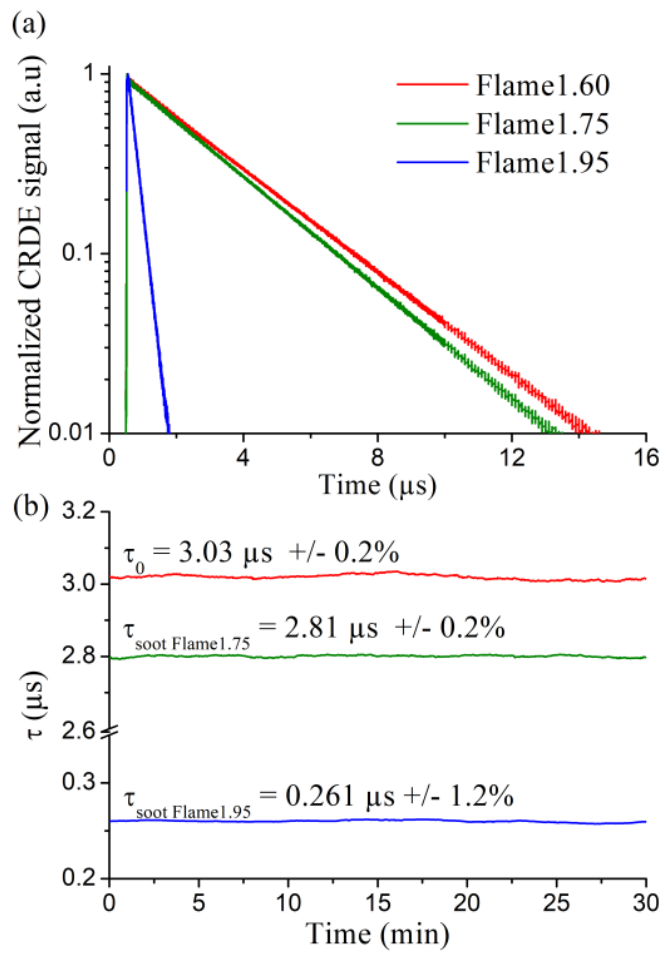

experiments using $1064 \mathrm{~nm}$ lasers [26-29].

Fig. 8 (b) shows the variations of the decay times with acquisition time measured every second during 30 minutes. These results illustrate both the good temporal stability of the CRDE cavity and the stability of the flames. To determine $\tau_{0}$, the decay time was measured in a non-sooting flame slightly below the equivalence ratio threshold at which soot particles can be detected using the LII or SMPS techniques. In this work, $\tau_{0}$ was measured in a soot-free flame of equivalence ratio 1.60 (Flame1.60) and was found constant along the burner axis, which suggests that the laser beam propagation in the cavity is not perturbed by the temperature gradient or does not experience additional absorptions. The CRDE signals were measured and averaged over 10 laser pulses. 

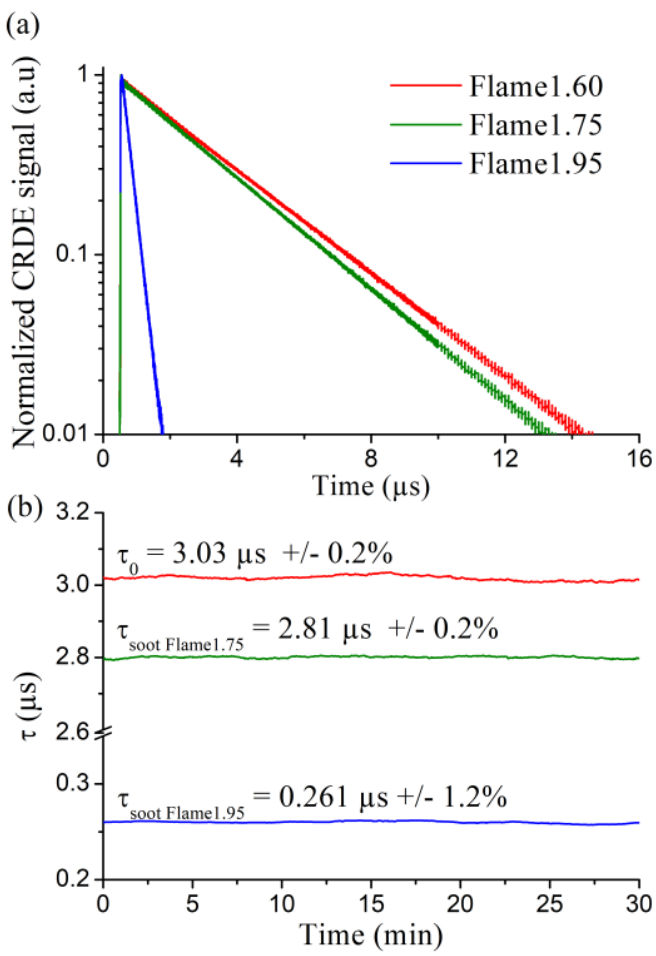

Fig. 8 CRDE signals recorded at $H A B=10 \mathrm{~mm}$ in sooting Flame1.95 and 1.75 and non-sooting Flame1.60 (a) and the corresponding pulse decay times as a function of acquisition time (b).

The measured CRDE decay-time enables the determination of the averaged extinction coefficient $\overline{K_{\lambda}^{e x t}}$ at $1064 \mathrm{~nm}$ using Eq. (3) and the flame diameter $l_{s}$.

It was found that $\overline{K_{\lambda}^{\text {ext }}}=7.6 \times 10^{-4} \mathrm{~cm}^{-1}\left(l_{s}=6.11 \mathrm{~cm}\right)$ in Flame 1.95 and $\overline{K_{\lambda}^{e x t}}=5.9 \times 10^{-6} \mathrm{~cm}^{-1}\left(l_{s}=5.6 \mathrm{~cm}\right)$ in Flame1.75 $(\mathrm{HAB}=10 \mathrm{~mm})$. Then from $\overline{K_{\lambda}^{e x t}}$, the axial values of $f_{\mathrm{v}}(\mathrm{x}=0, \mathrm{z}=10)$ at $\mathrm{HAB}=10 \mathrm{~mm}$ (see axis definition in Fig. 1) were derived following the same procedure as in [38], using Eq. 15 and considering the $E(m)$ values given in Section 4.1 (Table 1). The integration term on the right hand side is evaluated using the radial distribution of $f_{\mathrm{v}}$ as derived from the radial LII profiles obtained by 1D-LII imaging. In this transformation we have considered $E\left(m_{\lambda}\right)$ constant along the flame diameter.

$$
\begin{aligned}
& {\left[\int_{l_{s}} K_{\lambda}^{e x t} d x\right]_{z=10 m m}=\left[\overline{K_{\lambda}^{e x t}} l_{s}\right]_{z=10 m m}=6 \pi \frac{E\left(m_{\lambda}\right)}{\lambda} \int_{\frac{-l_{s}}{2}}^{\frac{l_{s}}{2}} f_{v}(x, z=10) d x=} \\
& 6 \pi \frac{E\left(m_{\lambda}\right)}{\lambda} f_{v}(0, z=10) \int_{-l_{s} / 2}^{l_{S} / 2} \frac{f_{v}(x, z=10)}{f_{v}(0, z=10)} d x
\end{aligned}
$$


The axial soot volume fractions were found to be $f_{\mathrm{v}} \approx 7.76 \mathrm{ppb}$ and $f_{\mathrm{v}} \approx 0.089 \mathrm{ppb}$ at $\mathrm{HAB}=10 \mathrm{~mm}$ in Flame1.95 and Flame1.75, respectively. Considering the uncertainties associated with the determination of the axial $f_{v}$ from the line-of-sight extinction measurements and on the absolute value of $E\left(m_{1064}\right)$, the uncertainty of $f_{v}$ measured by CRDE is estimated to be around $\pm 25 \%$.

\subsubsection{From LII signal to absolute soot volume fraction}

After derivation of the soot volume fraction in the calibration position, the LII signal intensity along each flame centerline is finally converted in absolute $f_{\mathrm{v}}$. Using Eq. (7), $f_{\mathrm{v}}(\mathrm{z})$ at any location can be determined knowing the absolute soot volume fraction $f_{\mathrm{v}}(10)$ at the calibration position $(10 \mathrm{~mm})$ using Eq. (16):

$\frac{f_{v(Z)}}{f_{v(10)}}=\frac{S_{L I I}\left(\lambda_{e m}, T_{(Z)}\right)}{S_{L I I}\left(\lambda_{e m}, T_{(10)}\right)} \frac{E\left(m_{\lambda_{e m}}\right)_{(10)}}{E\left(m_{\lambda_{e m}}\right)_{(H A B)}} \frac{I_{b b}\left(\lambda_{e m}, T_{(10)}\right)}{I_{b b}\left(\lambda_{e m}, T_{(Z)}\right)}$

The determination of $f_{\mathrm{v}(\mathrm{Z})}$ requires that each term on the right-hand side of Eq. (16) must be known. The blackbody intensity ratio $I_{b b}\left(\lambda_{e m}, T_{(Z)}\right) / I_{b b}\left(\lambda_{e m}, T_{(10)}\right)$ is commonly assumed to be equal to 1 in measurements using the conventional LII technique in which the LII signal is detected at only one spectral band in the visible by choosing the laser fluence in the plateau region of the fluence curve [48]. In these conditions, all the soot particles in the detection volume reach sublimation and their temperatures are assumed to be approximately equal and do not vary with fluence. In this study, there is no need to make any assumption for the intensity ratio $I_{b b}\left(\lambda_{e m}, T_{(Z)}\right) / I_{b b}\left(\lambda_{e m}, T_{(10)}\right)$, since it can be evaluated using the soot temperatures inferred from the ratio of LII signals detected at 532 and $650 \mathrm{~nm}$.

However, it is important to point out that the determination of soot temperature T using Eq. (9) requires the knowledge of the relative variation of $E(m)$ with wavelength at a given $\mathrm{HAB}$, i.e., $\mathrm{E}\left(\mathrm{m}_{\lambda_{2}}\right) / \mathrm{E}\left(\mathrm{m}_{\lambda_{1}}\right)$. This ratio may vary with flame conditions and soot maturity. It is commonly considered as unity $[52,53]$ in the visible range of the spectrum), though wavelength dependence of $E(m)$ has also been taken into account in some studies [13,19]. Recently, Simonsson et al. [9] 
considered a wavelength dependence of $E(m)$ with soot maturity $E\left(m_{\lambda}, \alpha\right)=\lambda^{1-\alpha} E(m)_{r e f}$, where $\alpha$ is a dispersion coefficient accounting for a deviation from the pure inverse relationship with $\lambda$ and $E(m)_{r e f}$ is the soot absorption function at a reference wavelength. It was found through analysis of the measured spectrally resolved extinction coefficients between 685 and $1064 \mathrm{~nm}$ that $\alpha$ = 1 for mature soot but tends towards 4 for incipient soot at low HABs where soot is newly nucleated. The value of $\alpha$ has a strong impact on the derived soot temperature. This illustrates that the inferred soot temperature and consequently the determination of $f_{\mathrm{v}}$ depend on the knowledge of the spectral variation of $E(m)$ with $\mathrm{HAB}$ or soot maturity. To date, there is a lack of accurate knowledge of how $E(m)$ varies with wavelength in the visible spectral range or with soot maturity mainly because of the difficulties in obtaining such knowledge both experimentally and theoretically.

In order to minimize the impact of the lack of knowledge about spectral variation of $E\left(m_{\lambda}\right)$ on $f_{v}$ determination, we have developed a new approach based on the joint measurement of LII and CRDE in the sooting flame (Flame1.95) and the nucleation flame (Flame1.75), i.e., flames containing soot with different characteristics. The approach proposed here takes advantage of the different dependence of the two techniques on $E\left(m_{\lambda}\right)$. The description of the approach starts with the ratios of the axial soot volume fractions between Flame1.95 and Flame1.75 at $\mathrm{HAB}=10 \mathrm{~mm}$ measured by both LII and CRDE. These ratios are then interpreted using different hypotheses on the wavelength dependence of $E\left(m_{\lambda \mathrm{em}}\right)$.

\section{- $\quad$ The ratio of the axial soot volume fractions measured by CRDE}

The ratio of $\mathrm{f}_{\mathrm{v}}$ between Flame1.95 and Flame1.75 at HAB = $10 \mathrm{~mm}$ obtained by CRDE (Eq. (3)) is only a function of the ratio of $E\left(m_{1064}\right)$ at $1064 \mathrm{~nm}$ corrected by a factor $\mathrm{C}_{\mathrm{i}}=\int_{\mathrm{l}_{\mathrm{s}}}\left(\mathrm{f}_{\mathrm{v}}(\mathrm{x}) / \mathrm{f}_{\mathrm{v}}^{\mathrm{i}}\right) \mathrm{dx}$, which takes into account the radial inhomogeneity of $\mathrm{f}_{\mathrm{v}}\left(\mathrm{f}_{\mathrm{v}}^{\mathrm{i}}\right.$ is the mean axial soot volume fraction over the width of 2C-LII collection volume in flame (i)), Eq. (17): 


$$
R_{f_{v}}^{C R D E}=\left(\frac{{ }^{1.95} f_{v}}{{ }^{1.75} f_{v}}\right)_{C R D E}=\frac{\int_{l_{S}} K_{1064}^{\text {ext }} d x}{\int_{l_{S}} K_{1064}^{\text {ext }} d x} \times \frac{{ }^{1.75} E\left(m_{1064}\right)}{1.95 E\left(m_{1064}\right)} \times \frac{C_{1.75}}{C_{1.95}}
$$

\section{- $\quad$ The ratio of the axial soot volume fractions measured by LII}

The soot volume fraction in each flame, measured by LII, is inferred from Eq. (7). By making the ratio of $\mathrm{f}_{\mathrm{v}}$ between Flame1.95 and Flame1.75 at $\mathrm{HAB}=10 \mathrm{~mm}$, one obtains (Eq. (18)). It is dependent on T and on the ratio of $E\left(m_{532}\right)$, in addition to the LII signals, as

$R_{f_{v}}^{L I I}=\left(\frac{1.95 f_{v}}{{ }^{1.75} f_{v}}\right)_{L I I}=\frac{{ }^{1.95} S_{L I I}\left(\lambda_{532}, T\right)}{{ }^{1.75} S_{L I I}\left(\lambda_{532}, T\right)} \times \frac{{ }^{1.75} I_{b b}\left(\lambda_{532}, T\right)}{{ }^{1.95} I_{b b}\left(\lambda_{532}, T\right)} \times \frac{{ }^{1.75} E\left(m_{532}\right)}{1.95 E\left(m_{532}\right)}$

It is important to point out that $\mathrm{f}_{\mathrm{v}}$ inferred from the prompt LII signal (the detected peak signal) is the instantaneous soot volume fraction at the moment of the peak LII signal and may suffer from a small amount of volume loss due to sublimation, which is also likely primary particle size dependent. In this study, the amount of volume loss at the peak LII signal at HAB $=10 \mathrm{~mm}$ in both flames was modelled using the LII model described in Section 3. To estimate the soot volume loss at $\mathrm{HAB}=10 \mathrm{~mm}$ in both Flame1.95 and Flame1.75, the values of $E(m)$, thermal properties, and primary particle size distribution reported in the recent study [26] were used in the LII model calculations following the methodology described by Liu and Smallwood [44]. It was found that the soot volume loss is about $3.6 \%$ at the moment of the peak LII signal at $\mathrm{HAB}=10 \mathrm{~mm}$ in both flames. It is noticed that all the volume or mass loss of soot particles quoted here is relative to the initial particle volume or mass. Considering the accuracy of the temporal LII peak determination, the mean soot volume loss was calculated over 2 ns around the peak LII signal and was found to be $5.17 \%$ in Flame1.95 and $4.15 \%$ in Flame1.75. Therefore, the effect of sublimation on the ratio ${ }^{1.95} \mathrm{f}_{\mathrm{v}, 10} /{ }^{1.75} \mathrm{f}_{\mathrm{v}, 10}$ determined by LII at the peak signal is less than $1.1 \%$ and can be neglected in the following analysis. It is worth pointing out, based on the results of LII modeling, that sublimation induces substantial amount of soot particle volume loss even at $10 \mathrm{~ns}$ after the peak of the LII signal. For example, at HAB = $10 \mathrm{~mm}$ in Flame1.75, 
the volume loss of soot particles increases rapidly from $3.6 \%$ to $18 \%$ from the peak of LII signal to 10 ns after the peak. However, the volume loss slows down quickly at later time due to the rapid cooling of such small particles. At 20 ns after the peak of LII signal, the soot particles only experience another $2.8 \%$ volume loss from that at $10 \mathrm{~ns}$ after the peak (from $18 \%$ to $20.8 \%$ ). These results indicate that the majority of soot particle volume (or mass) loss occurs within $10 \mathrm{~ns}$ after the peak of the LII signal and it is important to conduct soot volume fraction measurement at the peak of LII signal to minimize particle mass loss when conducting LII measurements of soot volume fraction using an approach similar to the present one in the high laser-fluence regime.

\section{- Comparison of the $\mathrm{f}_{\mathrm{v}}$ ratios obtained by LII and CRDE}

Taking the ratio of $R_{f_{v}}^{L I I}$ with $R_{f_{v}}^{C R D E}$ leads to Eq. (19):

$$
\begin{aligned}
& \mathrm{R}_{\mathrm{f}_{\mathrm{v}}}^{\mathrm{LII} / \mathrm{CRDE}}=\frac{R_{f_{v}}^{L I I}}{R_{f_{v}}^{C R D E}} \\
& =\frac{C_{1.95}}{C_{1.75}} \times \frac{\int_{\mathrm{l}_{\mathrm{s}}} \mathrm{K}_{1064}^{\mathrm{ext}} \mathrm{dx}}{\int_{\mathrm{l}_{\mathrm{s}}} \mathrm{K}_{1064}^{\mathrm{ext}} \mathrm{dx}} \times \frac{{ }^{1.95} S_{L I I}\left(\lambda_{532}, T\right)}{{ }^{1.75} S_{L I I}\left(\lambda_{532}, T\right)} \times \frac{{ }^{1.75} I_{b b}\left(\lambda_{532}, T\right)}{{ }^{1.95} I_{b b}\left(\lambda_{532}, T\right)} \times{ }^{1.75}\left(\frac{E\left(m_{532}\right)}{E\left(m_{1064}\right)}\right) \\
& \times^{1.95}\left(\frac{E\left(m_{1064}\right)}{E\left(m_{532}\right)}\right)
\end{aligned}
$$

The first term on the right-hand side of Eq. (19) reflects the radial distributions of soot at $H A B=10$ $\mathrm{mm}$ in both flames. The last three terms of Eq. (19) depend on the choice of how $E(m)$ varies with wavelength between 532 and $1064 \mathrm{~nm}$ and with soot maturity. It is expected that the ratio $\mathrm{R}_{\mathrm{f}_{\mathrm{v}}}^{\mathrm{LII} / \mathrm{CRDE}}$ is unity in theory because of the negligible variation of soot volume loss obtained in our prompt LII measurements. Therefore, the value of this ratio can be used as a criterion to evaluate the validity of different assumptions regarding the $E(m)$ variation with wavelength and soot maturity as shown below. 
4.2.3.1 Assumption 1: $E\left(m_{\lambda e m}\right)$ is not dependent on wavelength for a given soot in the range $[532-1064 \mathrm{~nm}]$

In this case, the ratio $R_{f_{v}}^{L I I / C R D E}$ given in Eq. (19) is reduced to the first four terms. Then two possibilities can be considered:

(1a) Variation of $\mathrm{T}$ is not taken into account.

This is equivalent to the assumption of constant peak soot temperature in the conventional LII technique operating in the plateau regime of the fluence curve. It means that the ratio of blackbody intensities in Eq. (19) is unity. Considering the standard deviations of LII signal (3\% in Flame1.95, 10\% in Flame1.75) and the uncertainty of $K_{1064}^{\text {ext }}$ estimated to $\pm 1.5 \%$, one obtains: ${ }^{1.95} S_{L I I}(\mathrm{~T}) /$ ${ }^{1.75} S_{L I I}(\mathrm{~T})=162 \pm 21$ and ${ }^{1.75} \int_{l_{\mathrm{s}}} \mathrm{K}_{1064}^{\mathrm{ext}} \mathrm{dx} /{ }^{1.95} \int_{\mathrm{l}_{\mathrm{s}}} \mathrm{K}_{1064}^{\mathrm{ext}} \mathrm{dx}=140 \pm 5$. Thus, the ratio $R_{f_{v}}^{L I I / C R D E}$ is equal to $1.14 \pm 0.18$. The LII signal ratio is $\sim 14 \%$ higher than the CDRE one.

(1b) Variation of $\mathrm{T}$ is taken into account in Eq. (19).

Under the assumption that $E(m)$ is independent of wavelength between 532 and $1064 \mathrm{~nm}$, $E\left(m_{1064}\right) / E\left(m_{532}\right)=1$, the soot temperature was obtained as $\mathrm{T}=4307 \mathrm{~K}$ in Flame 1.95 and $4186 \mathrm{~K}$ in Flame1.75 (Eq. (9)). With these temperatures, the ratio $I_{b b T}^{\lambda}$ is equal to $0.83 \pm 0.015$. Consequently, the ratios of $f_{v}$ in the two flames obtained by LII and CRDE are in much better agreement with $\mathrm{R}_{\mathrm{f}_{\mathrm{V}}}^{\mathrm{LII} / \mathrm{CRDE}}=0.95 \pm 0.18$

From the approach shown above it turns out that both LII and CRDE are able to reproduce the variation of $f_{\mathrm{v}}$ over a large dynamic range from the smallest incandescent soot particles (with size around 2- $4 \mathrm{~nm}$ ) in Flame1.75 to mature soot in Flame1.95 at $\mathrm{HAB}=10 \mathrm{~mm}$ (with primary particle diameters up to about $16 \mathrm{~nm}[26])$. In addition, the ratios of axial $f_{v}$ between the two flames determined by LII and CRDE agree well with or without consideration of soot temperature variation, 
though better agreement is achieved with correction of soot temperature variation. The only approximation made in the above analysis is that the absorption function $E(m)$ of soot does not vary between 532 and $1064 \mathrm{~nm}$ at $\mathrm{HAB}=10 \mathrm{~mm}$ in both Flame1.75 and Flame1.95.

4.2.3.2 Assumption 2: $\mathrm{E}\left(\mathrm{m}_{\lambda \mathrm{em}}\right)$ is dependent on both wavelength and soot maturity Under this assumption, the $E(m)$ model of Simonsson et al. [9] is considered. For this purpose, the last two terms of the ratio $R_{f_{v}}^{L I I / C R D E}$ are rearranged as follows:

$\mathrm{A}={ }^{1.75}\left(\frac{E\left(m_{532}\right)}{E\left(m_{1064}\right)}\right) \times{ }^{1.95}\left(\frac{E\left(m_{1064}\right)}{E\left(m_{532}\right)}\right)=\frac{1.75 E\left(m_{532}\right)}{1.95 E\left(m_{532}\right)} \frac{1.95 E\left(m_{1064}\right)}{1.75 E\left(m_{1064}\right)} \quad$ Eq. (20)

which indicates that the ratios of $E(m)$ at a given wavelength (532 and $1064 \mathrm{~nm}$ ) of soot particles of different maturities are required. In order to simulate the wavelength dependence of $E\left(m_{\lambda}\right)$ with the soot maturity, the equation $E\left(m_{\lambda}, \alpha\right)=\lambda^{1-\alpha} E(m)_{\text {ref }}$ (with $\lambda$ in $\mu \mathrm{m}$ ) is used to calculate the $f_{\mathrm{V}}$ ratios at $\mathrm{HAB}=10 \mathrm{~mm}$ by LII and CRDE within the $\alpha$ range obtained in [9]. In Flame1.95, the soot is considered fairly mature. Indeed, as shown Fig. 10, the $f_{v}$ profile in Flame1.95 reaches a plateau above $H A B=8 \mathrm{~mm}$, suggesting that the soot growth process has more or less ceased and the soot particles become mature. This conjecture is also supported by the value $E(m)=0.41$ at $10 \mathrm{~mm}$ derived in this work (Table 1), which is characteristic of mature soot. So it is reasonable to assign $\alpha_{1.95}=1$ and $E\left(m_{\lambda}\right)$ is constant between 532 and $1064 \mathrm{~nm}$. In Flame1.75, $E\left(m_{\lambda}\right)$ is calculated for different stages of soot maturity with $\alpha_{1.75}$ varying from 1 (mature soot) to 4 (first incandescent soot particles). Thus, the $E(m)$ ratio at $1064 \mathrm{~nm}$ is expressed as Eq. (21):

$\frac{{ }^{1.95} E\left(m_{1064}\right)}{{ }^{1.75} E\left(m_{1064}\right)}=\frac{1.064^{1-\alpha_{1.95}}}{1.064^{1-\alpha_{1.75}}}=1.064^{\alpha_{1.75}-1}$

and the $E(m)$ ratio at $532 \mathrm{~nm}$ is given as Eq. (22):

$\frac{{ }^{1.75} E\left(m_{532}\right)}{{ }^{1.95} E\left(m_{532}\right)}=\frac{0.532^{1-\alpha} 1.75}{0.532^{1-\alpha} 1.95}=0.532^{1-\alpha_{1.75}}$

Using the above two equations, we get $A=[1.064 / 0.532]^{\alpha_{1.75}-1}$. The ratio $E\left(m_{650}\right) / E\left(m_{532}\right)$ used in Eq. (9) to calculate $T$ is replaced by $(0.532 / 0.650)^{1-\alpha}$, with $\alpha$ being the respective value at 
$\mathrm{HAB}=10 \mathrm{~mm}$ in the two flames. The above expression of the ratio of $E(\mathrm{~m})$ allows to evaluate the sensitivity of $\mathrm{R}_{\mathrm{f}_{\mathrm{v}}}^{\mathrm{LII} / \mathrm{CRDE}}$ to $\alpha_{1.75}$.

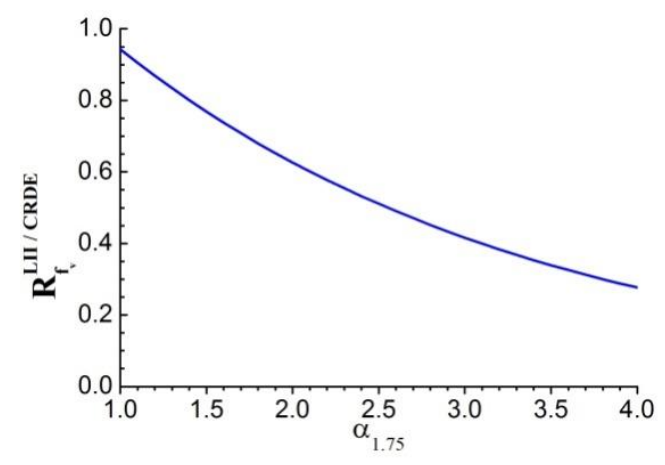

Fig. 9 Evolution of $R_{f_{v}}^{L I I / C R D E}$ as a function of $\alpha_{1.75}$

Fig. 9 displays $\mathrm{R}_{\mathrm{f}_{\mathrm{v}}}^{\mathrm{LII} / \mathrm{CRDE}}$ as a function of $\alpha_{1.75}$. It should be pointed out that the results reported in Table 1 were obtained using soot temperatures derived from the prompt LII signals detected at 532 and $650 \mathrm{~nm}$ with the assumption that $E(m)$ is wavelength independent between 532 and $1064 \mathrm{~nm}$. In the assessment of the potential impact of assuming wavelength dependence of $E(m)$ on the derived ratio shown in Fig. 9, such impact was considered in the determination of soot temperatures from the prompt LII signals and subsequent evaluation of the HAB dependence of $E(m)$ (Table 1 ) and the blackbody intensities ratio in Eq. (19). The result shows that the introduction of spectral dependence of $E(m)$ with soot maturity $\left(\alpha_{1.75}>1\right)$ in the spectral range of 532 to $1064 \mathrm{~nm}$ worsens significantly the consistency of the soot volume fraction ratio obtained by LII and CRDE. It is reasonable to assume that $R_{f_{v}}^{L I I}$ should be equal to $R_{f_{v}}^{C R D E}$ within experimental uncertainty, i.e., $\mathrm{R}_{\mathrm{f}_{\mathrm{v}}}^{\mathrm{LII} / \mathrm{CRDE}}$, Eq. (19) should be approximately unity. As such, the result shown in Fig. 9 leads to the conclusions that under the present experimental conditions $E\left(m_{\lambda}\right)$ is wavelength independent in the spectral range of 532 to $1064 \mathrm{~nm}$, regardless of the level of soot maturity. $E\left(m_{1064}\right) / E\left(m_{532}\right)=1$ yields the best agreement in soot volume fraction ratio between LII and CRDE measurements at HAB $=10 \mathrm{~mm}$ in the two flames. The absence of significant variation of $E\left(m_{\lambda}\right)$ between 532 and $1064 \mathrm{~nm}$ for soot particles of different maturities is consistent with observations by [24,34-36]. It contrasts 
with the previous work of Cleon et al. which reports a $30 \%$ decrease of $E\left(m_{532}\right) / E\left(m_{1064}\right)$ from incipient soot to mature soot in a premixed low pressure flame [54]. Concerning the observed variation of the ratio of $E(m)$ between 532 and $1064 \mathrm{~nm}$ in [54] (but not observed in the present paper), we do not have a satisfying explanation yet. The most plausible explanation may be due to the fact that the flame in [54] was stabilized at low pressure hence producing soot particles with different optical properties due to different degree of soot maturity. However the nearly constant value of $E\left(m_{532}\right) / E\left(m_{1064}\right)$ with soot maturity strongly contrats with the conclusions of Simonsson et al. [9]. It is not yet clear why our results differ from those obtained in [9]. It is noticed that the sensitivity and precision of single-path extinction measurements, as used in [9], is less than CRDE to make accurate extinction measurements in the nucleation zone of the investigated flames. In [9], the radial homogeneity of the soot distribution has not been controlled (at least it is not characterized) which might impact their conclusions. Furthermore, in [9] the dispersion coefficient ( $\alpha$ ) values were derived from extinction measurements between $685 \mathrm{~nm}$ and $1064 \mathrm{~nm}$ but then extended to shorter wavelengths. This procedure is also likely to increase the uncertainties in $\alpha$.

It is noticed that the absolute value of $E\left(m_{\lambda}\right)$ may increase with soot maturity. Based on the above considerations, the value of $E\left(m_{1064}\right)$ determined as a function of HAB in Section 3.1 (Table 1 ) is used to obtain the absolute axial $f_{\mathrm{v}}$ profiles from LII measurements using the $f_{\mathrm{v}}$ value from CRDE at $\mathrm{HAB}=10 \mathrm{~mm}$ as calibration.

\subsubsection{Absolute soot volume fraction profiles}

Fig. 10 displays the axial $f_{\mathrm{v}}$ profiles measured by CRDE (line-of-sight extinction converted in axial $f_{\mathrm{v}}$, see Section 3.2.2) and by LII in Flame1.95 and Flame1.75. The LII profiles have been converted in $f_{\mathrm{v}}$ profiles using Eq. (16) in which soot T (required to calculate the blackbody radiation intensity) was calculated using $E\left(m_{650}\right) / E\left(m_{532}\right)=1$ and the value $f_{v(10)}$ determined from CRDE measurement at $\mathrm{HAB}=10 \mathrm{~mm}$ in each flame: $f_{\mathrm{v}}=7.76 \mathrm{ppb}$ in Flame1.95 and $f_{\mathrm{v}}=0.089 \mathrm{ppb}$ in Flame1.75. The 
$E\left(m_{1064}\right)$ values obtained in Section 3.1 (Table 1 ) are used in both cases (LII and CRDE). The uncertainty on $f_{\mathrm{v}}$ (in relative value) is estimated to be $\pm 20 \%$ to which the uncertainty due to absolute calibration $( \pm 25 \%$ ) needs to be added.

The $f_{\mathrm{v}}$ profiles measured by CRDE and LII are in good agreement considering the uncertainties in both flames.

In this work the absolute soot volume faction could be determined independently in each flame by CRDE at $H A B=10 \mathrm{~mm}$. It is worth pointing out that if only one calibration value obtained for example in Flame1.95 at $\mathrm{HAB}=10 \mathrm{~mm}$ would have been used to calibrate the $f_{\mathrm{v}}$ profile of Flame1.75 by considering the raw LII ratios provided in Fig. 6 , the resulting $f_{\mathrm{v}}$ in Flame1.75 at $\mathrm{HAB}=10 \mathrm{~mm}$ would have been $0.048 \mathrm{ppb}$ instead of $0.089 \mathrm{ppb}$, i.e., underestimated by a factor 1.86 . This is mainly due to the differences in $E(m)$ and the peak soot temperature between the two flames, originated from different stages of maturity of soot particles. The correction of the raw LII ratio, by taking into account the variations of the temperature and $E(m)$ as developed in the previous sections, leads to a $f_{\mathrm{v}}$ value in Flame1.75 at $\mathrm{HAB}=10 \mathrm{~mm}$ of $0.095 \mathrm{ppb}$ in excellent agreement with the direct $f_{\mathrm{v}}$ value obtained by CRDE in the nucleation flame. This discussion indicates that it is important to account for the differences in $E(m)$ and temperature of soot particles in LII measurements between the calibration flame conditions and the measurement ones. This observation highlights the needs to consider the above variations to reduce the uncertainties on the $f_{\mathrm{v}}$ profiles. In both cases, the choice of constant $E\left(m_{\lambda}\right)$ in the range of 532-1064 nm gives a satisfactory agreement between LII and CRDE measurements. The consistency of the reported data supports the validity of these assumptions. 

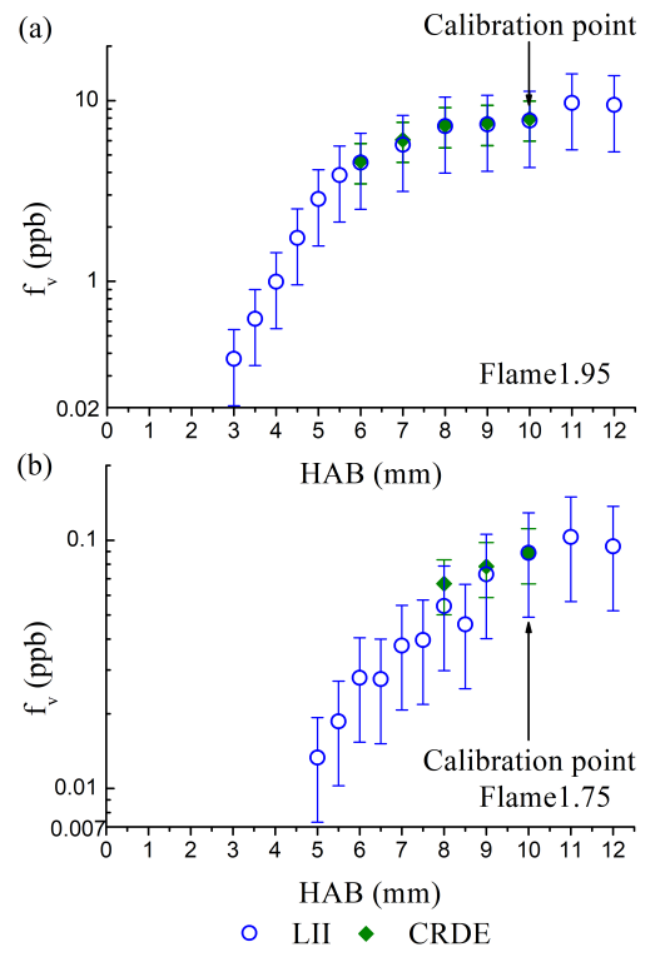

Fig. $10 f_{v}$ profiles obtained by CRDE or by LII. LII signals were corrected and calibrated by CRDE at $10 \mathrm{~mm}$ in each flame as detailed in sections 3.2.2 and 3.2.3.

\section{Conclusions}

The objective of this work is to determine the quantitative soot volume fraction profiles in two nbutane premixed sooting flames with equivalence ratios of 1.95 and 1.75 with very different stages of maturity and very different levels of soot volume fraction. The soot particle size distributions in these flames were previously investigated in [26]. Flame1.75 is a nucleation flame in which soot particles undergo only minor growth and have diameters in the range of 2-4 $\mathrm{nm}$. Flame1.95 is a more sooting flame with soot growth along $\mathrm{HAB}$. The main challenge of this work is the conversion of relative LII signals into absolute $f_{v}$ profiles reliably over a large dynamic range and for soot of different maturities.

We have proposed a strategy to take into account the variation of several soot properties $\left(E\left(m_{\lambda}\right), \mathrm{c}_{s}\right.$ and $\rho_{S}$ ) with soot maturity or to limit their impact on the accuracy of the quantitative determination of $f_{v}$. In particular, we developed a novel approach to assess the validity of assumption with regard 
to the spectral dependence of $E(\mathrm{~m})$ in the spectral range of 532 to $1064 \mathrm{~nm}$. The strategy consists of the following two aspects. First, the use of a suite of techniques: LII for axial profiles, LII for radial $f_{v}$ inhomogeneity, 2C-LII for soot temperature, LII modeling for evaluating the amount of soot volume loss at the LII signal peak due to sublimation, CRDE for LII calibration required to convert the relative LII signals to absolute $f_{v}$ profiles, and NO-LIF thermometry for gas temperature. The second aspect includes two novel approaches to analyze the LII and CRDE measurements. The first novel approach is proposed to determine the variation of $E\left(m_{\lambda_{1064}}\right) / \rho_{s} c_{s}$ with soot maturity based on the fact that the temperature increase of laser-heated soot is linear with fluence in the low fluence regime for $\mathrm{F}<0.15 \mathrm{~J} / \mathrm{cm}^{2}$. The variation of $E\left(m_{1064}\right)$ was then inferred with the help of an assumption of soot specific heat or the product $\rho_{s} c_{s}$. The second proposed approach takes advantage of the different dependence of LII and CRDE on $E(m)$ and the simple fact that the $f_{v}$ ratios between the two flames determined by LII should be the same as that determined by CRDE. This approach allows the validation of an assumption of the spectral variation of $E(m)$. It was found that the spectral variation of $E(m)$ is negligible in the range of 532-1064 $\mathrm{nm}$ in our conditions, contrasting with the conclusions of [9].

Based on assumptions that the density of smallest incandescent soot and mature soot is 1.3 and $1.8 \mathrm{~g} / \mathrm{cm}^{3}$, respectively, and temperature independent soot specific heat, $E\left(m_{1064}\right)$ was found to increase from 0.25 to 0.41 as the incipient soot evolves into more mature soot, resulting in an increase by only a factor 1.2 of $E\left(m_{1064}\right) / \rho_{s} c_{s}$ under the assumption that soot specific heat does not vary with soot maturity. This relatively small variation in $E\left(m_{1064}\right) / \rho_{s} c_{s}$ explains why the smallest incandescent soot particles can be heated nearly similarly as mature soot [26].

These analyses enable the conversion of the LII profiles, corrected for temperature and $E\left(m_{1064}\right)$, in absolute $f_{v}$ which extends from $0.013 \mathrm{ppb}$ to $9.7 \mathrm{ppb}$ in both flames. The relative accuracy is estimated to $20 \%$ and the absolute one to $45 \%$. The good agreement in the axial $f_{v}$ profiles measured by CRDE and LII using $1064 \mathrm{~nm}$ lasers once again confirms 
that soot particles in the nucleation flame and in the nucleation region of the more sooting flame as small as 2 to $4 \mathrm{~nm}$ are capable of absorbing and emitting light in the visible and near infrared.

\section{Acknowledgements}

Région "Hauts de France", Ministère de l'Enseignement Supérieur et de la Recherche (CPER Climibio), European Fund for Regional Economic Development and ANR-13-TDMO-0002 ASMAPE are thanked for their financial support. CaPPA project is funded by the French National Research Agency (Programme Investissement d'Avenir, contract ANR-11-LABX-0005). 
$\underline{\text { References }}$

1. H. Wang, Proceedings of the Combustion Institute 33, 41 (2011).

2. A. D'Anna, Proceedings of the Combustion Institute 32, 593 (2009).

3. D. Aubagnac-Karkar, A. El Bakali, and P. Desgroux, Combustion and Flame 189, 190 (2018).

4. C. Gu, H. Lin, J. Camacho, B. Lin, C. Shao, R. Li, H. Gu, B. Guan, Z. Huang, and H. Wang, Combustion and Flame 165, 177 (2016).

5. A. D. Abid, N. Heinz, E. D. Tolmachoff, D. J. Phares, C. S. Campbell, and H. Wang, Combustion and Flame 154, 775 (2008).

6. M. Commodo, G. De Falco, A. Bruno, C. Borriello, P. Minutolo, and A. D'Anna, Combustion and Flame 162, 3854 (2015).

7. M. M. Maricq, S. J. Harris, and J. J. Szente, Combustion and Flame 132, 328 (2003).

8. S. Chowdhury, W. R. Boyette, and W. L. Roberts, Journal of Aerosol Science 106, 56 (2017).

9. J. Simonsson, N.-E. Olofsson, S. Török, P.-E. Bengtsson, and H. Bladh, Appl. Phys. B 119, 657 (2015).

10. B. Tian, Y. Gao, S. Balusamy, and S. Hochgreb, Appl. Phys. B 120, 469 (2015).

11. H. Bladh, J. Johnsson, N.-E. Olofsson, A. Bohlin, and P.-E. Bengtsson, Proceedings of the Combustion Institute 33, 641 (2011).

12. S. Bejaoui, S. Batut, E. Therssen, N. Lamoureux, P. Desgroux, and F. Liu, Appl. Phys. B 118, 449 (2015).

13. S. Maffi, S. De luliis, F. Cignoli, and G. Zizak, Appl. Phys. B 104, 357 (2011).

14. F. Migliorini, K. A. Thomson, and G. J. Smallwood, Appl. Phys. B 104, 273 (2011).

15. T. C. Williams, C. R. Shaddix, K. A. Jensen, and J. M. Suo-Anttila, International Journal of Heat and Mass Transfer 50, 1616 (2007).

16. N. Moteki and Y. Kondo, Journal of Aerosol Science 39, 348 (2008).

17. H. A. Michelsen, C. Schulz, G. J. Smallwood, and S. Will, Progress in Energy and

Combustion Science 51, 2 (2015).

18. N.-E. Olofsson, J. Simonsson, S. Török, H. Bladh, and P.-E. Bengtsson, Appl. Phys. B 119, 669 (2015).

19. F. Goulay, P. E. Schrader, X. López-Yglesias, and H. A. Michelsen, Appl. Phys. B 112, 287 (2013).

20. H. A. Michelsen, F. Liu, B. F. Kock, H. Bladh, A. Boiarciuc, M. Charwath, T. Dreier, R. Hadef, M. Hofmann, J. Reimann, S. Will, P.-E. Bengtsson, H. Bockhorn, F. Foucher, K.-P.

Geigle, C. Mounaïm-Rousselle, C. Schulz, R. Stirn, B. Tribalet, and R. Suntz, Appl. Phys. B 87, 503 (2007).

21. C. M. Sorensen, Aerosol Science and Technology 35, 648 (2001).

22. P. Minutolo, G. Gambi, and A. D'Alessio, Symposium (International) on Combustion 26, 951 (1996).

23. J. Yon, R. Lemaire, E. Therssen, P. Desgroux, A. Coppalle, and K. F. Ren, Appl. Phys. B 104, 253 (2011).

24. K. O. Johansson, F. E. Gabaly, P. E. Schrader, M. F. Campbell, and H. A. Michelsen, Aerosol Science and Technology 51, 1333 (2017).

25. X. López-Yglesias, P. E. Schrader, and H. A. Michelsen, Journal of Aerosol Science 75, 43 (2014). 
26. C. Betrancourt, F. Liu, P. Desgroux, X. Mercier, A. Faccinetto, M. Salamanca, L. Ruwe, K. Kohse-Höinghaus, D. Emmrich, A. Beyer, A. Gölzhäuser, and T. Tritscher, Aerosol Science and Technology 51, 1 (2017).

27. P. Desgroux, A. Faccinetto, X. Mercier, T. Mouton, D. Aubagnac Karkar, and A. El Bakali, Combustion and Flame 184, 153 (2017).

28. T. Mouton, X. Mercier, M. Wartel, N. Lamoureux, and P. Desgroux, Applied Physics B 112, 369 (2013).

29. H. Bladh, N.-E. Olofsson, T. Mouton, J. Simonsson, X. Mercier, A. Faccinetto, P.-E. Bengtsson, and P. Desgroux, Proceedings of the Combustion Institute 35, 1843 (2015). 30. A. D'Alessio, A. D'Anna, P. Minutolo, and L. A. Sgro, in Combustion Generated Fine Carbonaceous Particles ed. by H. Bockhorn, A. D’Anna, A.F. Sarofim, H.Wang, KIT Scientific Publishing, p. 206, (2007).

31. L. A. Sgro, A. C. Barone, M. Commodo, A. D'Alessio, A. De Filippo, G. Lanzuolo, and P. Minutolo, Proceedings of the Combustion Institute 32, 689 (2009).

32. M. R. Kholghy, G. A. Kelesidis, and S. E. Pratsinis, Phys. Chem. Chem. Phys. 20, 10926 (2018).

33. E. Therssen, Y. Bouvier, C. Schoemaecker-Moreau, X. Mercier, P. Desgroux, M. Ziskind, and C. Focsa, Appl. Phys. B 89, 417 (2007).

34. S. Bejaoui, R. Lemaire, P. Desgroux, and E. Therssen, Appl. Phys. B 116, 313 (2014).

35. J. Yon, E. Therssen, F. Liu, S. Bejaoui, and D. Hebert, Appl. Phys. B 119, 643 (2015).

36. H. A. Michelsen, P. E. Schrader, and F. Goulay, Carbon 50, 740 (2012).

37. R. P. Bambha, M. A. Dansson, P. E. Schrader, and H. A. Michelsen, Appl. Phys. B 112, 343 (2013).

38. Y. Bouvier, C. Mihesan, M. Ziskind, E. Therssen, C. Focsa, J. F. Pauwels, and P. Desgroux, Proceedings of the Combustion Institute 31, 841 (2007).

39. P. Desgroux, X. Mercier, B. Lefort, R. Lemaire, E. Therssen, and J. F. Pauwels, Combustion and Flame 155, 289 (2008).

40. N.-E. Olofsson, H. Bladh, A. Bohlin, J. Johnsson, and P.-E. Bengtsson, Combustion Science and Technology 185, 293 (2013).

41. F. Migliorini, S. De luliis, F. Cignoli, and G. Zizak, Combustion and Flame 153, 384 (2008).

42. X. Mercier and P. Desgroux, in Cavity Ring-Down Spectroscopy: Techniques and Applications (Wiley-Blackwell, 2009), pp. 273-311.

43. R. L. Vander Wal and T. M. Ticich, Appl. Opt., 38, 1444 (1999).

44. F. Liu and G. J. Smallwood, Appl. Phys. B 112, 307 (2013).

45. H. A. Michelsen, The Journal of Chemical Physics 118, 7012 (2003).

46. E. Cenker and W. L. Roberts, Applied Physics B 123, 74 (2017).

47. F. Goulay, L. Nemes, P. E. Schrader, and H. A. Michelsen, Molecular Physics 108, 1013 (2010).

48. C. Schulz, B. F. Kock, M. Hofmann, H. Michelsen, S. Will, B. Bougie, R. Suntz, and G. Smallwood, Appl. Phys. B 83, 333 (2006).

49. D. R. Snelling, F. Liu, G. J. Smallwood, and Ö. L. Gülder, Combustion and Flame 136, 180 (2004).

50. H. A. Michelsen, P. E. Schrader, and F. Goulay, Carbon 48, 2175 (2010).

51. J. Yon, A. Bescond, and F.-X. Ouf, Journal of Aerosol Science 87, 28 (2015).

52. D. R. Snelling, K. A. Thomson, F. Liu, and G. J. Smallwood, Appl. Phys. B 96, 657 (2009).

53. J. Reimann, S.-A. Kuhlmann, and S. Will, Appl. Phys. B 96, 583 (2009). 
54. G. Cléon, T. Amodeo, A. Faccinetto, and P. Desgroux, Appl. Phys. B 104, 297 (2011). 